\title{
IDENTIDADE DOCENTE COM FOCO NO CENÁRIO DE PESQUISA: UMA REVISÃO SISTEMÁTICA
}

\author{
SANDRA RAQUEL DE ALMEIDA' \\ ORCID: https://orcid.org/0000-0003-0175-2805 \\ MARIA APARECIDA PENSO" \\ ORCID: https://orcid.org/0000-0003-1200-8088 \\ LEDA GONÇALVES DE FREITAS" \\ ORCID: https://orcid.org/0000-0002-1288-7134
}

I Centro de Ensino Superior do Brasil, Programa de Pós-Graduação e Licenciatura em Letras e Pedagogia, Valparaíso de Goiás, G0, Brasil.

II Universidade Católica de Brasília, Programa de Pós-Graduação em Psicologia, Brasília, DF, Brasil.

Sandra R. de Almeida - Mestre e Doutora em Psicologia pela Universidade Católica de Brasília. Professora da Secretaria de Estado de Educação do Distrito Federal. Professora de Pós-Graduação e Licenciatura em Letras e Pedagogia do Centro de Ensino Superior do Brasil de Valparaíso de Goiás.

E-mail: < sandraraquelalf@gmail.com $>$.

Maria A. Penso - Doutora em Psicologia Universidade de Brasília. Pós-Doutorado Programa de Pós-Graduação em Psicologia da Universidade Federal Fluminense. Coordenadora e professora do Programa de Pós-Graduação em Psicologia da Universidade Católica de Brasília, Distrito Federal. E-mail:<mariaaparecidapenso@gmail.com >.

Leda G. de Freitas - Doutora em Psicologia do Trabalho, Universidade de Brasília. Professora do Curso de Psicologia e do Programa de Pós-Graduação em Psicologia da Universidade Católica de Brasília, Distrito Federal. E-mail: < ledagfr@gmail.com >

RESUMO: Trata-se de um estudo bibliográfico que se utilizou do método de revisão sistemática. O objeto de estudo é a identidade docente. As bases de dados consultadas foram o Portal Capes, BVS e SciELO Brasil. Compuseram esta revisão trinta e três artigos. As categorias de análise das características definidoras da identidade docente foram: identidade missionária, identidade instrumental, identidade proletária e identidade profissional, a qual para cada uma delas foram criadas subcategorias que as representassem. Os resultados obtidos apontaram que a identidade docente é coabitada por estas categorias, sendo as mais frequentes, a identidade missionária e a identidade profissional. E, a menos frequente, a identidade proletária. Os estudos apontaram para a necessidade de investigações empíricas visando identificar as injunções sociológicas e psicológicas da trajetória do sujeito 
professor que se articulam na composição de suas identidades docentes e como ele lida com essas injunções no exercício de sua atuação profissional.

Palavras-chave: Revisão sistemática. Identidade. Identidade docente.

\section{TEACHING IDENTITY IN FOCUS IN THE RESEARCH SCENARIO: A SYSTEMATIC REVIEW}

ABSTRACT: It is a bibliographic study that used the systematic review method. The object of study is the teaching identity. The databases consulted were Portal Capes, BVS and SciELO Brazil. Thirty-three articles have compiled this review. The categories of analysis of the defining characteristics of the teaching identity were: missionary identity, instrumental identity, proletarian identity and professional identity, which for each of them were created subcategories that represented them The results obtained pointed out that the teaching identity is cohabited by these categories, the most frequent being missionary identity and professional identity. And less frequent, the proletarian identity. The studies pointed to the need for empirical investigations aiming at identifying the sociological and psychological injunctions of the trajectory of the subject teacher that are articulated in the composition of his teaching identities and how he deals with these injunctions in the exercise of his professional performance.

Keywords: Systematic review. Identity. Teaching identity.

\section{INTRODUĈ̣̃O}

Este artigo é fruto de investigação bibliográfica como parte integrante da pesquisa de Doutorado da primeira autora. Objetiva-se dar visibilidade à produção científica em torno da temática identidade docente por meio da metodologia de revisão sistemática. No intuito de consubstanciar esta investigação, o estudo orientou-se pelas seguintes questões de pesquisa: Quais são os contextos de pesquisas que têm atraído pesquisadores para investigar a temática identidade docente vinculada à área profissional da educação? Existem estudos publicados sobre identidade docente com foco no professor alfabetizador? Que fundamentos teóricos têm sido utilizados para conceituar identidade e identidade docente? Que características da identidade docente têm sido discutidas? 
Partindo destas indagações, constituiu-se como objetivos específicos: fazer um levantamento da produção científica sobre identidade docente vinculada à educação; identificar quais aportes teóricos vem sendo mais utilizados nas pesquisas para fundamentar o conceito de identidade e identidade docente; identificar quais características tem definido a identidade docente; verificar se dentre as pesquisas analisadas há menção ao professor alfabetizador.

\section{DESENHO METODOLÓGICO}

Esta revisão sistemática ocorreu em 2017 e 2018. Em 2017 consultou-se as bases de dados Portal Capes e BVS. A opção por utilizar a base BVS se deu pelo fato da pesquisa de doutoramento da primeira autora ser em psicologia. Após a conclusão desta busca verificou-se a necessidade de incluir base de dados próprio de armazenamento de pesquisas educacionais. Ao consultar outras bases de dados, optou-se por incluir a base Scielo Brasil. Esta opção teve como propósito visibilizar o que se tem circulado nos discursos acadêmicos sobre identidade no Brasil e países irmãos no sentido de ter como traço comum a localização geográfica, histórico de colonização e a miscigenação cultural. Após a busca realizada nestas três bases de dados, verificou-se que o descritor compatível à identidade docente indexado pela Thesaurus Brasileiro da Educação (Brased) corresponde à identidade profissional. Considerando a relevância para maior abrangência dos dados, optou-se por incluir na busca de informações esta última base de dados

Definido as bases de dados, Portal, Capes, BVS, Scielo Brasil e Thesaurus Brasileiro da Educação (Brased), delimitou-se os seguintes critérios de inclusão: corresponder à artigos publicados a partir de 2006; serem avaliados por pares; possuir pelo menos um autor com titulação de Doutorado; ter a expressão identidade docente ou outra similar que refere-se à identidade profissional do professor nos objetivos; ter como uma das temáticas centrais no corpo da pesquisa a questão da identidade docente. Para realizar a busca, utilizou-se o descritor "identidade docente" nas três primeiras bases. A opção pelo descritor "identidade docente se deu em função de já fazer uma primeira filtragem excluindo todas as pesquisas referentes à identidade profissional em outras áreas profissionais. Quanto à bases de dados Thesaurus Brasileiro da Educação (Brased), utilizou-se o descritor indexado "identidade profissional". O resultado da busca está apresentado no quadro a seguir, tendo sido eliminado os artigos já localizados nas bases anteriores: 
QUADRO 1. Busca Portal Capes, BVS, Scielo Brasil e Thesaurus Brasileiro da Educação (Brased)

\begin{tabular}{c|c|c|c|c} 
Descritor & $\begin{array}{c}\text { Resultado } \\
\text { Geral }\end{array}$ & $\begin{array}{c}\text { Resultado } \\
\text { Filtragem }\end{array}$ & $\begin{array}{c}\text { Inclusão } \\
\text { após leitura } \\
\text { do resumo }\end{array}$ & $\begin{array}{c}\text { Inclusão } \\
\text { após leitura } \\
\text { integral }\end{array}$ \\
\hline Portal Capes & 161 & 28 & 15 & 06 \\
\hline BVS & 227 & 67 & 32 & 10 \\
\hline SciELO Brasil & 156 & 32 & 22 & 17 \\
\hline $\begin{array}{c}\text { Thesaurus Brasileiro da } \\
\text { Educação (Brased) }\end{array}$ & 139 & 35 & 26 & 19 \\
\hline Total & 683 & 162 & 95 & 52
\end{tabular}

Conforme indica os dados, no Portal Capes foram encontradas cento e sessenta e uma pesquisas que atendiam aos critérios de inclusão relacionados ao período de abrangência, a avaliação por pares e a titulação dos autores. Foi utilizado como filtro o tópico em que o termo identidade fosse o tema central nos idiomas inglês, português e espanhol, resultando na permanência de vinte e oito artigos. Após a leitura dos resumos, eliminou-se os artigos que não atendiam o critério de constar a expressão identidade docente ou similar nos objetivos, ou por não corresponderem à pesquisa sobre identidade docente no âmbito educacional, restando um total de quinze artigos. Já a exclusão após a leitura integral foi por não ter a temática identidade docente como um dos aspectos centrais no corpo da pesquisa, resultando seis artigos incluídos desta base.

Em relação ao Portal BVS, com o descritor "identidade docente" localizou-se duzentos e vinte e sete pesquisas. No primeiro refinamento selecionou-se 'textos completos' e eliminou os repetidos na própria base e no Portal Capes, reduzindo para sessenta e sete artigos. Após a leitura do resumo, foram excluídos trinta e cinco artigos por abordarem a questão da identidade docente de outras profissões, ou por não constar a expressão identidade docente ou similar nos objetivos, reduzindo para trinta e dois artigos. Após a leitura integral foram incluídos desta base dez artigos.

A busca na base Scielo Brasil ocorreu em março de 2018 seguindo o mesmo processo metodológico de busca no Portal Capes. Com o descritor "identidade docente" foram localizados cento e cinquenta e seis artigos. Após refinar pelos critérios de inclusão 
e eliminar os repetidos nas bases anteriores, restaram trinta e dois artigos. Deste montante, dez foram excluídos pelo resumo e cinco após a leitura integral, resultando em dezessete artigos da base Scielo Brasil inseridos nesta revisão sistemática.

Em se tratando da base Thesaurus Brasileiro da Educação (Brased), a busca ocorreu em novembro de 2018, também seguindo os mesmos critérios metodológicos já utilizados, porém com o descritor "identidade profissional". Neste portal localizou-se cento e trinta e nove artigos. A partir da primeira filtragem e eliminando os repetidos nas bases anteriores, permaneceram trinta e cinco artigos. Destes, restaram vinte e seis após a leitura dos resumos e incluídos dezenove após a leitura integral. Assim, foram incluídos nesta revisão sistemática cinquenta e dois artigos publicados entre 2006 à 2018 sendo, seis retirados da base Portal Capes, dez da BVS, dezessete da Scielo Brasil e dezenove da Thesaurus Brasileiro da Educação (Brased).

$\mathrm{Na}$ organização dos dados, apresenta-se o conceito de identidade e de identidade docente retirado dos aportes teóricos apresentados nas pesquisas analisadas. Em seguida discute-se as características definidoras da identidade docente encontradas nas pesquisas que são aqui interpretadas a partir das categorias: identidade missionária; identidade instrumental;identidade proletária; e identidade profissional. Logo após, apresenta-se um panorama dos campos investigativos das pesquisas analisadas para situar o lugar destinado à identidade do professor alfabetizador no cenário de pesquisa. Nas considerações finais as autoras apresentam uma análise reflexiva sobre os avanços e lacunas que carecem de mais investimento investigativo.

\section{TRATAMENTO DOS DADOS}

\section{IDENTIDADE}

Neste item analisa como a questão da identidade foi tratada nas pesquisas que compuseram esta revisão sistemática e apresenta o conceito de identidade pela ótica dos referenciais que foram utilizados. Destes, treze são artigos teóricos e trinta e nove de pesquisas empíricas. Entre os critérios de inclusão adotados nesta revisão encontra-se: a necessidade de corresponder à publicações a partir de 2006; constar nos objetivos a expressão identidade docente ou similar; e, a temática identidade docente fazer parte da centralidade investigativa, estas informações podem ser visualizadas nos quadros a seguir: 
QUADRO 2. Demonstrativo dos artigos teóricos

\begin{tabular}{|c|c|c|}
\hline $\begin{array}{l}\text { PESOUISADOR } \\
\text { ANO }\end{array}$ & TEMÁTICA & OBJETIVO \\
\hline Oliveira, (2006) & $\begin{array}{l}\text { Consequências que a nova } \\
\text { regulação educativa na América } \\
\text { Latina tem tido sobre o trabalho } \\
\text { docente }\end{array}$ & $\begin{array}{l}\text { Discutir algumas consequências } \\
\text { que a nova regulação educativa na } \\
\text { América Latina tem tido sobre o } \\
\text { trabalho docente, sobretudo, as que } \\
\text { se referem às relações de trabalho } \\
\text { ou profissionalização e às relativas à } \\
\text { identidade docente. }\end{array}$ \\
\hline $\begin{array}{c}\text { Silva e Carvalho, } \\
\text { (2006) }\end{array}$ & $\begin{array}{l}\text { A dialética subjetividade e } \\
\text { objetividade no processo de } \\
\text { construção social da identidade } \\
\text { docente. }\end{array}$ & $\begin{array}{l}\text { Refletir sobre o processo de } \\
\text { constituição do ser e fazer-se } \\
\text { professor. }\end{array}$ \\
\hline Ferreira, (2007) & $\begin{array}{l}\text { Relaç̃ões entre a temática } \\
\text { identidade docente e o fenômeno } \\
\text { da sindicalização dos professores }\end{array}$ & $\begin{array}{l}\text { Discutir possíveis relações entre a } \\
\text { temática das identidades docentes } \\
\text { e o fenômeno da sindicalização do } \\
\text { professorado. }\end{array}$ \\
\hline Oliveira, (2008) & $\begin{array}{l}\text { Repercussões das reformas } \\
\text { educacionais mais recentes sobre } \\
\text { a identidade e profissionalização } \\
\text { docente. }\end{array}$ & $\begin{array}{l}\text { Observar as mudanças ocorridas na } \\
\text { organização do trabalho escolar e na } \\
\text { organização do trabalho docente. }\end{array}$ \\
\hline Teixeira, (2009) & $\begin{array}{l}\text { A docência a partir de múltiplos } \\
\text { condicionantes. }\end{array}$ & $\begin{array}{l}\text { Analisar o foco da formação de } \\
\text { professores e seus aspectos legais, } \\
\text { discutir os saberes e a identidade } \\
\text { profissional e apresentar reflexões } \\
\text { acerca da formação continuada de } \\
\text { professores. }\end{array}$ \\
\hline $\begin{array}{l}\text { Neto, Benites e } \\
\text { Silva, (2010) }\end{array}$ & $\begin{array}{l}\text { Elementos que constituem o } \\
\text { habitus profissional de professor, } \\
\text { tendo na construção da identidade } \\
\text { docente o ponto de partida. }\end{array}$ & $\begin{array}{l}\text { Identificar nos elementos constituintes } \\
\text { do habitus profissional de professor as } \\
\text { categorias pedagógicas que possam } \\
\text { contribuir para uma possível "gênese" } \\
\text { da profissão docente pautada nos } \\
\text { saberes, práticas, valores. }\end{array}$ \\
\hline $\begin{array}{l}\text { Faria e Souza, } \\
\qquad \text { (2011) }\end{array}$ & $\begin{array}{l}\text { Conceito de identidade em } \\
\text { pesquisas sobre formação de } \\
\text { professores. }\end{array}$ & $\begin{array}{l}\text { Compreender como o conceito de } \\
\text { identidade tem sido apropriado } \\
\text { nas pesquisas sobre formação de } \\
\text { professores e sua contribuição para } \\
\text { a compreensão do processo de } \\
\text { constituição da identidade docente. }\end{array}$ \\
\hline
\end{tabular}




\begin{tabular}{|c|c|c|}
\hline $\begin{array}{l}\text { Cruz e Aguiar, } \\
\text { (2011) }\end{array}$ & $\begin{array}{l}\text { Relação entre a noção de } \\
\text { identidade e profissionalidade } \\
\text { á macroestrutura e suas } \\
\text { repercussões na profissionalização } \\
\text { docente. }\end{array}$ & $\begin{array}{l}\text { Relacionar a noção de identidade e de } \\
\text { profissionalidade à macroestrutura } \\
\text { e suas repercussões na } \\
\text { profissionalização docente; bem como } \\
\text { identificar o sentido dessa construção } \\
\text { coletiva, os modelos de profissão que } \\
\text { alimentam as ações e a identidade } \\
\text { profissional docente nos diferentes } \\
\text { contextos socioprofissionais. }\end{array}$ \\
\hline $\begin{array}{l}\text { Morgado, } \\
\text { (2011) }\end{array}$ & $\begin{array}{l}\text { Desafios e problemas que a escola } \\
\text { e o professores enfrentam na } \\
\text { atualidade }\end{array}$ & $\begin{array}{l}\text { Refletir sobre alguns dos problemas } \\
\text { com que atualmente se confrontam } \\
\text { a escola e os professores e que } \\
\text { tem dificultado a melhoria de suas } \\
\text { práticas. }\end{array}$ \\
\hline Tateo, (2012) & $\begin{array}{l}\text { Dimensões da identidade } \\
\text { profissional do Professor na } \\
\text { investigação psicológica e } \\
\text { educacional }\end{array}$ & $\begin{array}{l}\text { Explorar as dimensões da Identidade } \\
\text { Profissional do Professor na } \\
\text { investigação psicológica e educacional } \\
\text { e apresentar diferentes respostas } \\
\text { para perguntas como: que dimensões } \\
\text { foram tidas em conta na definição de } \\
\text { professor? }\end{array}$ \\
\hline $\begin{array}{l}\text { Alves, Calsa e } \\
\text { Moreli, (2015) }\end{array}$ & $\begin{array}{l}\text { Processos de formação e de } \\
\text { construção da identidade docente. }\end{array}$ & $\begin{array}{l}\text { Problematizar as questões relativas } \\
\text { aos processos de formação e de } \\
\text { construção da identidade docente } \\
\text { e ao papel que as experiências } \\
\text { vividas em suas trajetórias pessoais } \\
\text { e profissionais desempenham neste } \\
\text { contexto. }\end{array}$ \\
\hline $\begin{array}{l}\text { Matos, Nista- } \\
\quad \text { Piccolo e } \\
\text { Borges, (2016) }\end{array}$ & $\begin{array}{l}\text { Identidade profissional do professor } \\
\text { de Educação Física }\end{array}$ & $\begin{array}{l}\text { Discorrer sobre a identidade } \\
\text { profissional docente com enfoque na } \\
\text { identidade do professor de Educação } \\
\text { Física. }\end{array}$ \\
\hline $\begin{array}{c}\text { Vozniak, } \\
\text { Mesquita e } \\
\text { Batista, (2016) }\end{array}$ & $\begin{array}{l}\text { Identidade e identidade } \\
\text { profissional. }\end{array}$ & $\begin{array}{l}\text { Cartografar a investigação em língua } \\
\text { portuguesa de } 2003 \text { a } 2013 \text { no campo } \\
\text { da identidade e identidade profissional. }\end{array}$ \\
\hline
\end{tabular}

Fonte: Criada pela primeira autora

Nos treze artigos teóricos, identificou-se as seguintes temáticas articuladas à questão da identidade docente: as consequências que a nova regulação educativa na América Latina tem tido sobre o trabalho docente (OLIVEIRA, 2006; 2008); subjetividade e objetividade na construção social da identidade docente (SILVA; CARVALHO, 
2006); o fenômeno da sindicalização dos professores (FERREIRA, 2007); a docência a partir de múltiplos condicionantes (TEIXEIRA, 2009); desafios e problemas que a escola e o professores enfrentam na atualidade (MORGADO, 2011); elementos que constituem o habitus profissional de professor (NETO; BENITES; SILVA, 2010); O conceito de identidade em pesquisas sobre formação de professores (FARIA; SOUZA, 2011); a noção de profissionalidade relacionada à macroestrutura e suas repercussões na profissionalização docente (CRUZ; AGUIAR, 2011); a investigação psicológica e educacional (TATEO, 2012); os processos de formação com foco nas metodologias que envolvem narrativas biográficas (ALVES; CALSA; MORELI, 2015); a identidade profissional do professor de Educação Física (MATOS; NISTA-PICCOLO; BORGES, 2016); e, identidade e identidade profissional (VOZNIAK; MESQUITA; BATISTA, 2016).

QUADRO 3. Demonstrativo dos artigos empíricos.

\begin{tabular}{|c|l|l|}
\hline $\begin{array}{c}\text { PESQUISADOR } \\
\text { ANO }\end{array}$ & \multicolumn{1}{|c|}{ TEMÁTICA } & \multicolumn{1}{c|}{ OBJETIVo } \\
\hline $\begin{array}{c}\text { Oliveira et al. } \\
\text { (2006) }\end{array}$ & $\begin{array}{l}\text { Relações aprendizagem-identidade } \\
\text { e teoria-prática }\end{array}$ & $\begin{array}{l}\text { Colaborar para a compreensão das } \\
\text { relações aprendizagem, identidade e } \\
\text { teoria-prática de professores. }\end{array}$ \\
\hline $\begin{array}{c}\text { Aguiar, (2006) } \\
\text { Gentil, (2006) }\end{array}$ & $\begin{array}{l}\text { Formação continuada de } \\
\text { professores e sua implicação na } \\
\text { identidade docente }\end{array}$ & $\begin{array}{l}\text { Estudar a identidade docente com } \\
\text { foco na formação continuada de } \\
\text { professores. }\end{array}$ \\
\hline $\begin{array}{c}\text { Monteiro, } \\
\text { (2006) }\end{array}$ & $\begin{array}{l}\text { Construçãade da professor e a rede de dentidade } \\
\text { profissional docente }\end{array}$ & $\begin{array}{l}\text { Investigar como se constituem as } \\
\text { identidades de professores. }\end{array}$ \\
\hline $\begin{array}{c}\text { Alves-Mazoti, } \\
\text { (2007) }\end{array}$ & $\begin{array}{l}\text { Representações da identidade } \\
\text { docente. }\end{array}$ & $\begin{array}{l}\text { Não identificado } \\
\text { Identificar as representações sociais } \\
\text { da "identidade profissional docente" de } \\
\text { professores. }\end{array}$ \\
\hline $\begin{array}{c}\text { Salvadori, } \\
\text { (2007) }\end{array}$ & $\begin{array}{l}\text { Lembranças da infância e } \\
\text { juventude de professores. }\end{array}$ & $\begin{array}{l}\text { Investigar o modo como as lembranças } \\
\text { da infância e juventude de professores } \\
\text { se relacionam ao processo de } \\
\text { constituição da cultura escolar e se } \\
\text { tem peso na construção da identidade } \\
\text { profissional. }\end{array}$ \\
\hline Identidade profissional & $\begin{array}{l}\text { Evidenciar os processos e movimentos } \\
\text { por meio dos quais damos sentido à } \\
\text { nossa identidade de professores/as. }\end{array}$ \\
\hline
\end{tabular}




\begin{tabular}{|c|c|c|}
\hline Ojeda, (2008) & Características de la identidade. & $\begin{array}{l}\text { Describe algunas características de la } \\
\text { identidad del docente. }\end{array}$ \\
\hline Malatér, (2008) & Construção Identitária. & $\begin{array}{l}\text { Investigar como uma futura professora } \\
\text { de língua inglesa narra parte de sua } \\
\text { constituição identitária, }\end{array}$ \\
\hline $\begin{array}{c}\text { Oliveira e } \\
\text { Grigoli, (2008) }\end{array}$ & $\begin{array}{l}\text { Relações entre a trajetória escolar } \\
\text { e a construção da identidade } \\
\text { profissional. }\end{array}$ & $\begin{array}{l}\text { Identificar quais os saberes que se } \\
\text { originam das primeiras vivências com a } \\
\text { escola e que os docentes mobilizam no } \\
\text { exercício da prática profissional. }\end{array}$ \\
\hline $\begin{array}{l}\text { Vieira, Hypólito } \\
\text { e Duarte, } \\
\text { (2009) }\end{array}$ & $\begin{array}{l}\text { Dispositivos de controle, como } \\
\text { regulação conservadora e suas } \\
\text { interferências na fabricação da } \\
\text { identidade profissional. }\end{array}$ & $\begin{array}{l}\text { Discutir dispositivos de controle, } \\
\text { como regulação conservadora, e suas } \\
\text { interferências tanto no processo de } \\
\text { trabalho de professoras em início de } \\
\text { carreira quanto na fabricação de suas } \\
\text { identidades profissionais. }\end{array}$ \\
\hline $\begin{array}{l}\text { Vergueiro, } \\
\text { (2009) }\end{array}$ & $\begin{array}{l}\text { Identidade de professor e suas } \\
\text { raízes profundas na personalidade }\end{array}$ & $\begin{array}{l}\text { Esclarecer ao leitor alguns dos } \\
\text { fundamentos básicos que a psicologia } \\
\text { analítica utiliza para compreender } \\
\text { a identidade do professor e seus } \\
\text { fundamentos na personalidade. }\end{array}$ \\
\hline $\begin{array}{l}\text { Mieles-Barrera, } \\
\text { Henríquez- } \\
\text { Linero e } \\
\text { Sánchez- } \\
\text { Castellón, } \\
\text { (2009) }\end{array}$ & $\begin{array}{l}\text { Aspetos pessoais e profissionais } \\
\text { que caracterizam os professores de } \\
\text { educação infantil. }\end{array}$ & $\begin{array}{l}\text { Generar entre los participantes } \\
\text { procesos de reflexión y reconocimiento } \\
\text { sobre los aspectos que los } \\
\text { caracterizan, a nivel personal y } \\
\text { professional. }\end{array}$ \\
\hline $\begin{array}{l}\text { Matheus e } \\
\text { Nacorato, } \\
\text { (2009) }\end{array}$ & $\begin{array}{l}\text { Constituição da identidade do } \\
\text { professor. }\end{array}$ & $\begin{array}{l}\text { Analisar como os professores } \\
\text { percebiam as influências das políticas } \\
\text { públicas em seus fazer cotidiano. }\end{array}$ \\
\hline $\begin{array}{l}\text { Brando e } \\
\text { Caldeira, } \\
\text { (2009) }\end{array}$ & $\begin{array}{l}\text { Perspectivas de atuação } \\
\text { profissional de alunos de Ciências } \\
\text { Biológicas. }\end{array}$ & $\begin{array}{l}\text { Levantar as expectativas dos alunos } \\
\text { em relação ao curso e qual identidade } \\
\text { profissional construíram como parte do } \\
\text { imaginário que compõe o ethos. }\end{array}$ \\
\hline $\begin{array}{l}\text { Figueiredo, } \\
\text { (2010) }\end{array}$ & $\begin{array}{l}\text { Experiências profissionais, } \\
\text { formação e identidades da/na } \\
\text { docência. }\end{array}$ & $\begin{array}{l}\text { Discutir sobre a identidade profissional } \\
\text { de base e as dimensões que } \\
\text { circunscrevem dela, relacionada à } \\
\text { formação, experiências e trajetórias. }\end{array}$ \\
\hline Assis, (2010) & $\begin{array}{l}\text { Representações sociais da ação } \\
\text { docente e constituição identitária }\end{array}$ & $\begin{array}{l}\text { Analisar as representações sociais } \\
\text { que orientam as ações docentes e a } \\
\text { constituição identitária. }\end{array}$ \\
\hline
\end{tabular}




\begin{tabular}{|c|c|c|}
\hline $\begin{array}{l}\text { Hernandez, } \\
\text { (2011) }\end{array}$ & $\begin{array}{l}\text { Significados que mobilizam os } \\
\text { docentes de educação básica. }\end{array}$ & $\begin{array}{l}\text { Analiza, a partir de las autobiografías, } \\
\text { los significados que movilizan los } \\
\text { docentes de educación básica en } \\
\text { su encuentro con las instituciones } \\
\text { escolares. }\end{array}$ \\
\hline $\begin{array}{l}\text { Sales e } \\
\text { Chamon, } \\
(2011)\end{array}$ & $\begin{array}{l}\text { Fatores intervenientes na escolha } \\
\text { profissional e a influência desses } \\
\text { elementos na constituição da } \\
\text { identidade profissional docente }\end{array}$ & $\begin{array}{l}\text { Analisar os fatores intervenientes } \\
\text { na escolha da profissão, assim como } \\
\text { a influência desses elementos na } \\
\text { construção da identidade profissional } \\
\text { docente. }\end{array}$ \\
\hline $\begin{array}{l}\text { Cunha e } \\
\text { Cardozo, } \\
(2011)\end{array}$ & $\begin{array}{l}\text { A relação entre a formação inicial } \\
\text { do professor e a percepção que ele } \\
\text { tem da docência. }\end{array}$ & $\begin{array}{l}\text { Investigar a profissão do educador } \\
\text { de História através de sua identidade } \\
\text { narrativa. }\end{array}$ \\
\hline $\begin{array}{l}\text { Nakagome, } \\
\text { (2012) }\end{array}$ & $\begin{array}{l}\text { Identidade docente como objeto de } \\
\text { reflexão. }\end{array}$ & $\begin{array}{l}\text { Discutir a importância de que a } \\
\text { identidade docente seja objeto de } \\
\text { reflexão e discussão nos cursos de } \\
\text { formação continuada de professores. }\end{array}$ \\
\hline $\begin{array}{c}\text { Tejerina e } \\
\text { Gutman, (2012) }\end{array}$ & $\begin{array}{l}\text { A (re)estabilização identitária do } \\
\text { professor no contexto do ensino de } \\
\text { História. }\end{array}$ & $\begin{array}{l}\text { Discute situações interculturais e a } \\
\text { estabilidade identitária do professor. }\end{array}$ \\
\hline $\begin{array}{l}\text { Souza, Petroni } \\
\text { e Andrada, } \\
\text { (2013) }\end{array}$ & $\begin{array}{l}\text { Aspectos envolvidos na } \\
\text { constituição da identidade docente } \\
\text { e o papel da afetividade. }\end{array}$ & $\begin{array}{l}\text { Investigar os aspectos envolvidos na } \\
\text { constituição da identidade docente, em } \\
\text { especial o papel da afetividade. }\end{array}$ \\
\hline $\begin{array}{l}\text { D'aura-Tardeli, } \\
\text { (2013) }\end{array}$ & $\begin{array}{l}\text { Avaliando valores em escolares e } \\
\text { seus professores. }\end{array}$ & $\begin{array}{l}\text { Avaliar a identidade profissional de } \\
\text { professores relacionada a valores que } \\
\text { estabelecem como prioritários. }\end{array}$ \\
\hline $\begin{array}{l}\text { Raitz e Silva, } \\
\text { (2014) }\end{array}$ & $\begin{array}{l}\text { Trajetória identitária e os sentidos } \\
\text { atribuídos ao trabalho docente. }\end{array}$ & $\begin{array}{l}\text { Compreender a trajetória identitária } \\
\text { de professoras e analisar os sentidos } \\
\text { atribuídos por elas ao trabalho } \\
\text { docente. }\end{array}$ \\
\hline $\begin{array}{l}\text { Costa e } \\
\text { Rezende, } \\
\text { (2014) }\end{array}$ & $\begin{array}{l}\text { Formação da identidade docente } \\
\text { e sua relação constitutiva com a } \\
\text { linguagem. }\end{array}$ & $\begin{array}{l}\text { Investigar a construção discursiva da } \\
\text { identidade docente. }\end{array}$ \\
\hline Bellido, (2015) & La construcción de la identidad. & $\begin{array}{l}\text { Explorar la construcción narrativa de la } \\
\text { identidad de un docente. }\end{array}$ \\
\hline $\begin{array}{c}\text { Miranda e } \\
\text { Chaves, (2015) }\end{array}$ & $\begin{array}{l}\text { Configurações e contradições dos } \\
\text { sentidos do processo identitário. }\end{array}$ & $\begin{array}{l}\text { Analisar as configurações e } \\
\text { contradições dos sentidos do processo } \\
\text { identitário do professor. }\end{array}$ \\
\hline $\begin{array}{l}\text { Rosa e Ramos, } \\
\qquad(2015)\end{array}$ & $\begin{array}{l}\text { Relaç̃oes entre processos } \\
\text { identitários docentes, reformas } \\
\text { curriculares e a noção de disciplina } \\
\text { escolar. }\end{array}$ & $\begin{array}{l}\text { Investigar relaç̃oes entre processos } \\
\text { identitários docentes, reformas } \\
\text { curriculares em nível de Ensino Médio } \\
\text { e a noção de disciplina escolar. }\end{array}$ \\
\hline
\end{tabular}




\begin{tabular}{|c|c|c|}
\hline $\begin{array}{l}\text { Villarruel } \\
\text { Fuentes, Pérez } \\
\text { Santiago e } \\
\text { Alarcón Silva, } \\
\text { (2015) }\end{array}$ & $\begin{array}{l}\text { La caracterización de la identidad } \\
\text { de un colectivo de maestros. }\end{array}$ & $\begin{array}{l}\text { Invetigar la caracterización de la } \\
\text { identidad de profesores. }\end{array}$ \\
\hline Flores, (2015) & $\begin{array}{l}\text { Conceito de identidade profissional } \\
\text { à luz da literatura internacional. }\end{array}$ & $\begin{array}{l}\text { Compreender o modo como os alunos } \\
\text { veem o currículo da formação inicial } \\
\text { com destaque especial para o lugar } \\
\text { da prática na configuração de sua } \\
\text { identidade profissional. }\end{array}$ \\
\hline Soares, (2015) & $\begin{array}{l}\text { Aspectos da identidade profissional } \\
\text { de professores do Colégio Pedro II. }\end{array}$ & $\begin{array}{l}\text { Conhecer e compreender aspectos da } \\
\text { identidade profissional de professores. }\end{array}$ \\
\hline $\begin{array}{c}\text { Baladeli, } \\
\text { Borstel e } \\
\text { Ferreira, (2016) }\end{array}$ & $\begin{array}{l}\text { Conceitos de identidades docentes } \\
\text { e diferença. }\end{array}$ & $\begin{array}{l}\text { Identificar, nos discursos de } \\
\text { professores quais os sentidos que } \\
\text { estes sujeitos constroem sobre a } \\
\text { profissão professor. }\end{array}$ \\
\hline $\begin{array}{l}\text { Quilaqueo, } \\
\text { Quintriqueo } \\
\text { e Riquelme, } \\
\text { (2016) }\end{array}$ & $\begin{array}{l}\text { La construcción de la identidad } \\
\text { profesional. }\end{array}$ & $\begin{array}{l}\text { Explorar la construcción de la identidad } \\
\text { profesional de docentes. }\end{array}$ \\
\hline $\begin{array}{l}\text { Allain e } \\
\text { Coutinho, } \\
\text { (2017) }\end{array}$ & $\begin{array}{l}\text { Controvérsia envolvendo a } \\
\text { identidade profissional. }\end{array}$ & $\begin{array}{l}\text { Mapear a controvérsia envolvendo a } \\
\text { identidade profissional de licenciandos } \\
\text { em Ciências Biológicas. }\end{array}$ \\
\hline Oliveira, (2017) & $\begin{array}{l}\text { Bagagens deixadas pelo Programa } \\
\text { Institucional de Bolsas de } \\
\text { Iniciação à Docência (PIBID) } \\
\text { aos licenciandos em relação à } \\
\text { formação inicial docente e à } \\
\text { construção de suas identidades } \\
\text { profissionais. }\end{array}$ & $\begin{array}{l}\text { Investigar as bagagens deixadas pelo } \\
\text { PIBID a licenciandos no que tange } \\
\text { à sua formação inicial docente e } \\
\text { à construção de suas identidades } \\
\text { profissionais. }\end{array}$ \\
\hline $\begin{array}{l}\text { Obara, Broietti } \\
\text { e Passos, } \\
\text { (2017) }\end{array}$ & $\begin{array}{l}\text { Contribuição do PIBID para a } \\
\text { construção da identidade docente. }\end{array}$ & $\begin{array}{l}\text { Caracterizar a contribuição do PIBID } \\
\text { para a construção da identidade } \\
\text { docente. }\end{array}$ \\
\hline $\begin{array}{l}\text { Buitrago-Bonilla } \\
\text { e Cárdenas- } \\
\text { Soler, (2017) }\end{array}$ & $\begin{array}{l}\text { Los aspectos relacionados con la } \\
\text { identidad y las emociones. }\end{array}$ & $\begin{array}{l}\text { Apresentar resultados concernentes } \\
\text { aos aspectos relacionados com a } \\
\text { identidade e as emoções estudantes } \\
\text { de dos programas de formação de } \\
\text { maestros. }\end{array}$ \\
\hline $\begin{array}{l}\text { Martins e } \\
\text { Anunciato, } \\
\text { (2018) }\end{array}$ & $\begin{array}{l}\text { Constituição da identidade } \\
\text { docente. }\end{array}$ & $\begin{array}{l}\text { Compreender como se expressam, nas } \\
\text { narrativas, os indícios de constituição } \\
\text { da identidade docente de licenciandos. }\end{array}$ \\
\hline
\end{tabular}

Fonte: Criada pela primeira autora 
No que se refere à centralidade da temática identidade docente, nas trinta e nove pesquisas empíricas, os resultados encontrados foram os seguintes:

a) A construção da identidade docente (MONTEIRO, 2006; GENTIL, 2006; SALVADORI, 2007; CUNHA et al., 2007; OLIVEIRA; GRIGOLI, 2008; MALATER, 2008; MATHEUS; NACORATO, 2009; BRANDO; CALDEIRA, 2009; SALES; CHAMON, 2011;SOUZA; PETRONE; ANDRADA, 2013; COSTA; REZENDE, 2014; FLORES, 2015; BELIDO, 2015; QUILAQUEO; QUINTRIQUEO; RIQUELME, 2016; OLIVEIRA, 2017; OBARA; BROIETTI; PASSOS, 2017; MARTINS; ANUNCIATO, 2018).

b) Formação, atuação profissional e identidade docente (OLIVEIRA et al., 2006; AGUIAR, 2006; FIGUEIREDO, 2010; CUNHA, CARDOZO, 2011; NAKAGOME, 2012).

c) Características da identidade docente (OJEDA, 2008; MIELESBARRERA, HENRÍQUEZ-LINERO; SÁNCHEZ-CASTELLÓN, 2009; VILLARRUEL FUENTES; PÉREZ SANTIAGO; ALARCÓN SILVA, 2015; SOARES, 2015).

d) Sentidos e significações articulados à identidade docente (HERNANDEZ, 2011 RAITZ; SILVA, 2014; MIRANDA; CHAVES, 2015).

e) As representações construídas pelos professores sobre a identidade docente (ALVES-MAZOTI, 2007; ASSIS, 2010).

f) Dispositivos de controle, como regulação conservadora e sua repercussão na identidade docente (VIEIRA; HIPÓLITO; DUARTE, 2009).

g) As raízes profundas da identidade do professor (VERGUEIRO, 2009).

h) A (re)estabilização identitária do professor no contexto do ensino (TEJERINA; GUTMAN, 2012).

i) Avaliação da identidade profissional relacionada à valores (D'AURATARDELI, 2013).

j) As relações entre processos identitários docentes, reformas curriculares e a noção de disciplina escolar (ROSA; RAMOS, 2015).

k) Os conceitos de identidades docentes e diferença (BALADELI; BORSTEL; FERREIRA, 2016). 
1) A controvérsia envolvendo a identidade profissional docente (ALLAIN; COUTINHO, 2017).

m) Os aspectos relacionados com a identidade e as emoções (BUITRAGO-BONILLA; CÁRDENAS-SOLER, 2017).

De acordo com os dados encontrados, a temática identidade docente tem despertado o interesse dos pesquisadores no período analisado. Observa-se uma intensa mobilização em torno da construção da identidade docente, sendo alvo de investigação de dezesseis de um total de trinta e nove pesquisas. Em segundo lugar encontra-se a identidade docente relacionada à formação e atuação profissional, presente em seis pesquisas. A terceira posição aparece a questão relacionada às características da identidade docente, revelada em quatro pesquisas. Em quarto lugar com três pesquisas localizouse a questão do sentido e significações relacionados à identidade docente. Em quinto lugar, presente em duas pesquisas, identificou as representações atribuídas à identidade docente. Por último, sendo tema de interesse em uma pesquisa, apareceram as questões com alguma especificidade que não foi possível situá-las nas questões mais abrangentes mencionadas acima.

Revela-se ainda que, entre 2006 e 2018 houve publicações todos os anos. 2015, com o total de sete pesquisas publicadas, seis empíricas e uma teórica, ocupou a liderança. Em segundo lugar aparece com seis publicações, três teóricas e três empíricas, o ano de 2006; seis empíricas em 2009; e, três teórica e três empíricas em 2011. Em terceiro lugar com quatro pesquisas cada, vieram os anos de, 2007 e 2008 com uma teórica e três empíricas; e, 2016 com duas teórica e duas empíricas. Em 2010, 1012 e 2017 houveram três publicações, sendo uma teórica e duas empíricas; e apenas empíricas respectivamente. Em 2013 e 2014 localizou-se duas pesquisa sendo todas empíricas. Por último com uma pesquisa empírica ficou o ano de 2018.

Verificou-se também que, apesar da questão identitária estar em voga, apresentar o conceito de identidade fundamentado teoricamente não tem sido uma preocupação de parcela considerável dos autores das publicações localizadas. No quadro abaixo pode-se verificar esta constatação e identificar os teóricos mencionados nas respectivas pesquisas para fundamentar tal conceito. 
Quadro 4. Demonstrativo da fundamentação do conceito de identidade.

\begin{tabular}{|c|c|c|}
\hline $\begin{array}{c}\text { TEÓRICO } \\
\text { REFERENCIADO }\end{array}$ & CONCEITO & AUTOR/ANO \\
\hline \multirow{12}{*}{$\begin{array}{l}\text { (DUBAR, } \\
\text { 1991; 1995; } \\
\text { 1997; 2005) }\end{array}$} & \multirow{12}{*}{$\begin{array}{l}\text { A formação identitária se concretiza } \\
\text { por um movimento em que congregam } \\
\text { as atribuiç̃ões que o sujeito recebe do } \\
\text { social e o sentimento de pertença do } \\
\text { sujeito que identifica com as atribuições } \\
\text { recebidas. Sendo assim, a atribuição é } \\
\text { o sentido identitário advindo do social, } \\
\text { enquanto que o sentimento de pertença } \\
\text { corresponde à identidade para si. }\end{array}$} & Matheus e Nacorato (2009) \\
\hline & & Figueiredo (2010) \\
\hline & & Faria e Souza (2011) \\
\hline & & Nakagome (2012) \\
\hline & & D'aura-Tardeli (2013) \\
\hline & & Raitz e Silva (2014) \\
\hline & & Soares (2015) \\
\hline & & $\begin{array}{l}\text { Matos, Nista-Piccolo e Borges } \\
\text { (2016) }\end{array}$ \\
\hline & & Vozniak, Mesquita e Batista (2016) \\
\hline & & Quilaqueo et al., (2016) \\
\hline & & Baladeli et al., (2016) \\
\hline & & Martins e Anunciato (2018) \\
\hline \multirow{8}{*}{$\begin{array}{l}\text { (HALL, 1997; } \\
\text { 2003; 2006; } \\
\text { 2011) }\end{array}$} & \multirow{8}{*}{$\begin{array}{l}\text { A identidade é construída por meio do } \\
\text { pertencimento às diversas dimensões } \\
\text { culturais, étnicas, raciais, linguísticas, } \\
\text { religiosas e nacionais. Dessa forma, } \\
\text { as mudanças que ocorrem no cerne } \\
\text { das culturas afetam diretamente a } \\
\text { identidade pessoal. }\end{array}$} & Cunha et al. (2007) \\
\hline & & Cruz e Aguiar (2011) \\
\hline & & Faria e Souza (2011) \\
\hline & & Costa e Rezende (2014) \\
\hline & & Rosa e Ramos (2015) \\
\hline & & Alves et al., (2015) \\
\hline & & Baladeli et al., (2016) \\
\hline & & $\begin{array}{l}\text { Matos, Nista-Piccolo e Borges } \\
(2016)\end{array}$ \\
\hline
\end{tabular}




\begin{tabular}{|c|c|c|}
\hline \multirow{6}{*}{$\begin{array}{l}\text { (CIAMPA, } \\
\text { 1987; 1989; } \\
\text { 1991; 1994; } \\
\text { 2001) }\end{array}$} & \multirow{6}{*}{$\begin{array}{l}\text { A identidade é compreendida como um } \\
\text { processo de constante transformação, } \\
\text { algo também temporário, resultante } \\
\text { do entrelaçamento da história pessoal } \\
\text { do sujeito com seu contexto sócio } \\
\text { histórico e seus projetos. Possui caráter } \\
\text { dinâmico em um movimento que origina } \\
\text { uma personagem que corresponde a } \\
\text { vivência pessoal de um papel produzido } \\
\text { antecipadamente e padronizado pela } \\
\text { cultura. Ela é construída a partir da } \\
\text { articulação entre igualdade e diferença. }\end{array}$} & Silva e Carvalho (2006) \\
\hline & & Matheus e Nacorato (2009) \\
\hline & & Brando e Caldeira (2009) \\
\hline & & Faria e Souza (2011) \\
\hline & & Miranda e Chaves (2015) \\
\hline & & Martins e Anunciato (2018) \\
\hline \multirow[b]{2}{*}{$\begin{array}{l}\text { (ERIKSON, } \\
1976)\end{array}$} & \multirow[b]{2}{*}{$\begin{array}{l}\text { Os processos identitários pautam-se pelo } \\
\text { mecanismo de introjeção, que significa a } \\
\text { apropriação do outro, e pelo mecanismo } \\
\text { de identificação, que representa a } \\
\text { escolha de outros que lhe é significativo. } \\
\text { Por meio dessa dinâmica instala-se a } \\
\text { relação entre o sujeito e seu contexto } \\
\text { social. Há também um desejo constante } \\
\text { do sujeito em ser reconhecido pelo outro } \\
\text { presente na constituição da identidade. }\end{array}$} & Aguiar (2006) \\
\hline & & Cruz e Aguiar (2011) \\
\hline \multirow[b]{2}{*}{$\begin{array}{l}\text { (BAUMAN, } \\
2005)\end{array}$} & \multirow[b]{2}{*}{$\begin{array}{l}\text { A construção identitária encontra } \\
\text { sua base nas interações sociais que } \\
\text { geram vínculos estáveis. Todavia, } \\
\text { esta identidade só se revela em meio } \\
\text { a instabilidade, dando lhe um caráter } \\
\text { de ambivalência que busca ao mesmo } \\
\text { tempo a união e a divisão, fazendo com } \\
\text { que a inclusão e segregação sejam par } \\
\text { dialético complementares. }\end{array}$} & Matheus e Nacorato (2009) \\
\hline & & Faria e Souza (2011) \\
\hline $\begin{array}{l}\text { (CARDOSO, } \\
\text { BATISTA } \\
\text { E GRAÇA, } \\
2016 \text { ) }\end{array}$ & $\begin{array}{l}\text { A identidade é um fenômeno complexo } \\
\text { que incorpora uma dimensão individual } \\
\text { que é compreendida como núcleo da } \\
\text { personalidade; e, uma dimensão coletiva } \\
\text { que remete a um nível de análise } \\
\text { grupal ou coletivo. Porém, essas duas } \\
\text { dimensões precisam ser consideradas } \\
\text { como interdependentes. }\end{array}$ & Martins e Anunciato (2018) \\
\hline $\begin{array}{l}\text { (MELUCCI, } \\
\text { 2001) }\end{array}$ & $\begin{array}{l}\text { Na identidade individual ou de grupos } \\
\text { está presente três características: a } \\
\text { permanência que é a continuidade do } \\
\text { sujeito/grupo no tempo e nas variações } \\
\text { do ambiente; a delimitação entre sujeito/ } \\
\text { grupo que permite sua distinção; e } \\
\text { a manifestação da capacidade de } \\
\text { reconhecer-se e ser reconhecido. }\end{array}$ & Gentil (2006) \\
\hline
\end{tabular}

Fonte: Criada pela primeira autora. 
Conforme retrata o quadro acima, dos cinquenta e dois artigos desta revisão, somente vinte e dois conceituam identidade. Dentre estes, cinco são teóricos e dezessete empíricos. Dois fazem menção à abordagem que orienta a pesquisa, mas não apresenta o conceito. E, os vinte e oito artigos restantes, não apresentam o conceito de identidade.

Dentre os teóricos que fundamentam o conceito de identidade, o maior destaque vai para Dubar com doze citações (MATHEUS e NACORATO, 2009; FIGUEIREDO, 2010; FARIA; SOUZA, 2011; CRUZ; AGUIAR, 2011; D’AURA-TARDELI, 2013; RAITZ; SILVA, 2014; SOARES, 2015; MATOS, NISTA-PICCOLO e BORGES, 2016; VOZNIAK, MESQUITA e BATISTA, 2016; QUILAQUEO; QUINTRIQUEO; RIQUELME, 2016; MARTINS; ANINCIATO, 2018); e um (OLIVEIRA, 2017), cita sem conceituar. O segundo teórico da lista mais citado trata-se de Stuart Hall, sendo mencionado em oito pesquisas (CUNHA et al., 2007; FARIA; SOUZA, 2011; NAKAGOME, 2012; COSTA; REZENDE, 2014; ROSA; RAMOS, 2015; ALVES; CALSA; MORELI, 2015; BALADELI, BORSTEL; FERREIRA, 2016; MATOS, NISTA-PICCOLO e BORGES, 2016). Ciampa ocupou a terceira colocação estando, presente em seis artigos (SILVA e CARVALHO, 006; MATHEUS e NACORATO, 2009; BRANDO e CALDEIRA, 2009; FARIA; SOUZA, 2011; MIRANDA; CHAVES, 2015; MARTINS; ANINCIATO, 2018). Eric Erikson é citado em três pesquisas, sendo que duas delas (AGUIAR, 2006; CRUZ; AGUIAR, 2011), apresenta o conceito de identidade por ele desenvolvido. Já a terceira (BUITRAGO-BONILLA; CÁRDENAS-SOLER, 2017), apesar de situar sua investigação a partir desta concepção de identidade, não apresenta o conceito. Quanto à Bauman, duas pesquisas (MATHEUS; NACORATO, 2009; FARIA E SOUZA, 2011) apresentaram o conceito de identidade por ele desenvolvido. Malucci foi citado na conceituação de identidade em um das pesquisas analisada (GENTIL, 2006). Em outra pesquisa (MARTINS; ANINCIATO, 2018), o conceito de identidade foi referenciado por Cardoso, Batista e Graça.

\section{IDENTIDADE DOCENTE}

Quanto ao conceito de identidade docente, este está presente em vinte e nove das cinquenta e duas pesquisas analisadas. As definições e referenciais utilizados podem ser verificado no quadro abaixo. 
Quadro 5. Demonstrativo da fundamentação do conceito de identidade docente.

\begin{tabular}{|c|c|c|}
\hline $\begin{array}{c}\text { TEÓRICO } \\
\text { REFERENCIADO }\end{array}$ & CONCEITO & AUTOR/ANO \\
\hline \multirow{18}{*}{$\begin{array}{l}\text { (NÓVOA, 1986; } \\
\text { 1987; 1989; } \\
\text { 1995; 1992; } \\
\text { 2000; 2007; } \\
\text { 2013) }\end{array}$} & \multirow{18}{*}{$\begin{array}{l}\text { A identidade docente trata-se de uma } \\
\text { construção social, complexa e dinâmica. } \\
\text { Caracteriza-se pela maneira como cada um } \\
\text { se sente e se diz professor. É construída } \\
\text { por meio de posturas produzidas individual e } \\
\text { coletivamente, como fruto do diálogo entre } \\
\text { os mundos objetivo e subjetivo do indivíduo, } \\
\text { de suas condições cotidianas de trabalho, do } \\
\text { imaginário acerca da profissão de professor } \\
\text { e dos discursos que circulam no mundo } \\
\text { social e cultural da escola e dos docentes. }\end{array}$} & Silva e Carvalho (2006) \\
\hline & & Monteiro (2006) \\
\hline & & Ferreira (2007) \\
\hline & & Cunha et al. (2007) \\
\hline & & Salvadori (2007) \\
\hline & & Oliveira (2008) \\
\hline & & $\begin{array}{l}\text { Matheus e Nacorato } \\
\text { (2009) }\end{array}$ \\
\hline & & Teixeira (2009) \\
\hline & & Sales e Chamon, (2011) \\
\hline & & Nakagome (2012) \\
\hline & & Costa; Rezende, (2014) \\
\hline & & $\begin{array}{l}\text { Alves, Calsa e Moreli } \\
\text { (2015) }\end{array}$ \\
\hline & & Flores (2015) \\
\hline & & $\begin{array}{l}\text { Vozniak, Mesquita e } \\
\text { Batista (2016) }\end{array}$ \\
\hline & & $\begin{array}{l}\text { Matos, Nista-Piccolo e } \\
\text { Borges (2016) }\end{array}$ \\
\hline & & Baladeli et al., (2016) \\
\hline & & Obara et al., (2017) \\
\hline & & $\begin{array}{l}\text { Martins; Anunciato } \\
\text { (2018) }\end{array}$ \\
\hline
\end{tabular}




\begin{tabular}{|c|c|c|}
\hline \multirow{11}{*}{$\begin{array}{l}\text { (PIMENTA, } \\
\text { 1996; 1998; } \\
\text { 1999; 2000; } \\
\text { 2005; 2012; } \\
\text { PIMENTA; LIMA } \\
\text { 2004; PIMENTA; } \\
\text { ANASTASIOU, } \\
\text { 2002; 2008) }\end{array}$} & \multirow{11}{*}{$\begin{array}{l}\text { A construção das identidades docentes } \\
\text { está baseada nos valores de cada um, em } \\
\text { como cada um constrói sua história de vida, } \\
\text { no modo de situar-se no mundo de cada } \\
\text { professor, nas suas representações, nos } \\
\text { seus saberes, em suas angústias e anseios, } \\
\text { no sentido que tem em sua vida o ser } \\
\text { professor. }\end{array}$} & Monteiro (2006) \\
\hline & & Teixeira (2009) \\
\hline & & Figueiredo, (2010) \\
\hline & & Sales e Chamon, (2011) \\
\hline & & Cruz e Aguiar (2011) \\
\hline & & Baladeli et al., (2016) \\
\hline & & $\begin{array}{l}\text { Matos, Nista-Piccolo e } \\
\text { Borges (2016) }\end{array}$ \\
\hline & & $\begin{array}{l}\text { Vozniak, Mesquita e } \\
\text { Batista (2016) }\end{array}$ \\
\hline & & Obara et al., (2017) \\
\hline & & Oliveira, (2017) \\
\hline & & $\begin{array}{l}\text { Allain e Coutinho, } \\
\text { (2017) }\end{array}$ \\
\hline \multirow{3}{*}{ (TARDIF, 2002) } & \multirow{3}{*}{$\begin{array}{l}\text { A identidade docente se constitui a partir do } \\
\text { exercício da docência levando o sujeito a se } \\
\text { tornar professor. }\end{array}$} & Ferreira (2007) \\
\hline & & D'aura-Tardeli (2013) \\
\hline & & $\begin{array}{l}\text { Matos, Nista-Piccolo e } \\
\text { Borges (2016) }\end{array}$ \\
\hline \multirow[b]{2}{*}{$\begin{array}{l}\text { (MARCELO, } \\
\text { 2009) }\end{array}$} & \multirow{2}{*}{$\begin{array}{l}\text { A identidade docente constitui a partir das } \\
\text { identificações que se vai estabelecendo no } \\
\text { campo de atuação desta profissão passando } \\
\text { pela formação inicial e pelos diferentes } \\
\text { espaços institucionais numa dimensão } \\
\text { espacial e temporal. }\end{array}$} & Oliveira, (2017) \\
\hline & & $\begin{array}{l}\text { Martins; Anunciato } \\
\text { (2018) }\end{array}$ \\
\hline \multirow[b]{2}{*}{ (LIBÂNEO, 2001) } & \multirow{2}{*}{$\begin{array}{l}\text { A construção da identidade docente ocorre } \\
\text { ao longo das experiências e a graduação } \\
\text { ocupa lugar de destaque por oferecer } \\
\text { um espaço-tempo de construção de “um } \\
\text { conjunto de conhecimentos, habilidades, } \\
\text { atitudes, valores que definem e orientam a } \\
\text { especificidade do trabalho do professor. }\end{array}$} & $\begin{array}{l}\text { Allain e Coutinho, } \\
\text { (2017) }\end{array}$ \\
\hline & & $\begin{array}{l}\text { Matos, Nista-Piccolo e } \\
\text { Borges (2016) }\end{array}$ \\
\hline \multirow[b]{2}{*}{ (BOLIVAR, 2006) } & \multirow{2}{*}{$\begin{array}{l}\text { Identidade profissional docente é o modo } \\
\text { como os professores constroem a natureza } \\
\text { do seu trabalho. É o significado que esse } \\
\text { professor atribui à sua profissão. }\end{array}$} & D'aura-Tardeli (2013) \\
\hline & & $\begin{array}{l}\text { Matos, Nista-Piccolo e } \\
\text { Borges (2016) }\end{array}$ \\
\hline
\end{tabular}




\begin{tabular}{|c|c|c|}
\hline $\begin{array}{l}\text { (VEIRAVÉ et al., } \\
\text { 2006) }\end{array}$ & $\begin{array}{l}\text { A construção da identidade docente envolve } \\
\text { planos pessoal e coletivo. Não se constitui } \\
\text { de forma independente e em isolamento, mas } \\
\text { em um cenário de atuação do sujeito e em } \\
\text { um contexto social mais amplo. Conjuga-se } \\
\text { o privado e o público, o profissional e o } \\
\text { pessoal. }\end{array}$ & $\begin{array}{l}\text { Mieles-Barrera et al., } \\
\text { (2009) }\end{array}$ \\
\hline $\begin{array}{l}\text { (CORREIA, 1991; } \\
\text { LOPES, 1993) }\end{array}$ & $\begin{array}{l}\text { A identidade docente é resultante de um } \\
\text { processo complexo de relações no âmbito } \\
\text { profissional em diferentes espaços sociais, } \\
\text { envolvendo os saberes específicos, as } \\
\text { condições simbólicas e imaginárias, o } \\
\text { contexto sócio-técnico-organizacional } \\
\text { do trabalho, a natureza das relações que } \\
\text { estabelecem. }\end{array}$ & Cruz e Aguiar (2011) \\
\hline $\begin{array}{l}\text { (MIZUKAMI; } \\
\text { REALI, 2002; } \\
\text { BORBA, 2001) }\end{array}$ & $\begin{array}{l}\text { A identidade docente congrega os } \\
\text { significados advindos das pertenças ao } \\
\text { modelo 'ser professor', construído na relação } \\
\text { afetiva, durante a socialização primária e } \\
\text { mediante outras representações políticas, } \\
\text { religiosas, étnicas e culturais advindas do } \\
\text { grupo familiar, da comunidade e da sua } \\
\text { classe social. }\end{array}$ & Sales; Chamon, (2011) \\
\hline $\begin{array}{l}\text { KERBY (1991); } \\
\text { LASKY, 2005; } \\
\text { IANNACCONE } \\
\text { et al., 2008; } \\
\text { LIGORIO; TATEO, } \\
\text { 2008) }\end{array}$ & $\begin{array}{l}\text { A identidade é um processo dinâmico que } \\
\text { envolve interpretação, reinterpretação e } \\
\text { auto avaliação das experiências de vida. } \\
\text { Envolve três níveis de análise: um nível } \\
\text { individual, incluindo biografia pessoal do } \\
\text { professor e dinâmica de posicionamento; um } \\
\text { nível interpessoal, incluindo relacionamento } \\
\text { social, práticas e artefatos; e um nível } \\
\text { cultural, incluindo representações, normas, } \\
\text { valores e organização do contexto. }\end{array}$ & Tateo (2012) \\
\hline $\begin{array}{l}\text { (HALL, 2006; } \\
\text { LARROSA, 2006; } \\
\text { HERNÁNDEZ, } \\
\text { 2005; SILVA, } \\
\text { 2012; SANTOS, } \\
\text { 1999) }\end{array}$ & $\begin{array}{l}\text { A identidade docente é construída por meio } \\
\text { das interações do sujeito com o meio social, } \\
\text { levando em consideração seus interesses } \\
\text { pessoais, as exigências que a ele é atribuída } \\
\text { no decorrer de sua trajetória, as vivências } \\
\text { coletivas, as relações de poder juntamente } \\
\text { com sua prática docente. }\end{array}$ & $\begin{array}{l}\text { Alves, Calsa e Moreli } \\
\text { (2015) }\end{array}$ \\
\hline (RAMÍREZ; 2008) & $\begin{array}{l}\text { A identidade docente trata-se de uma } \\
\text { construção histórica, sendo cambiante e } \\
\text { reconhecida por seu caráter valorativo em } \\
\text { que os sujeitos se identificam por seu status } \\
\text { representativo de poder e prestígio. }\end{array}$ & Bellido (2015) \\
\hline
\end{tabular}




\begin{tabular}{|c|c|c|}
\hline TELLES (2002) & $\begin{array}{l}\text { A identidade profissional docente se } \\
\text { constitui por meio das interações sociais, } \\
\text { das oportunidades formativas, das } \\
\text { experiências de vida, das trajetórias } \\
\text { escolares assumindo dimensões distintas ao } \\
\text { longo da história de cada um. }\end{array}$ & Baladeli et al., (2016) \\
\hline $\begin{array}{l}\text { (ÁVALOS; } \\
\text { SOTOMAYOR, } \\
\text { 2012) }\end{array}$ & $\begin{array}{l}\text { Há quatro elementos de identidade } \\
\text { associados com o exercício da docência, } \\
\text { sendo eles: a vocação para a docência } \\
\text { representada pelos motivos da escolha } \\
\text { profissional envolvendo os valores pessoais; } \\
\text { a contribuição social, que está associada } \\
\text { à profissão como recurso para ajudar } \\
\text { no progresso individual dos alunos; as } \\
\text { condições de trabalho; e a influência de } \\
\text { modelos (professores, da família) na escolha } \\
\text { da profissão docente. }\end{array}$ & Quilaqueo et al., (2016) \\
\hline $\begin{array}{l}\text { (COSTA; BEJA; } \\
\text { REZENDE, 2014) }\end{array}$ & $\begin{array}{l}\text { A identidade docente se constitui mediante } \\
\text { um acúmulo de significados e representações } \\
\text { carregados de valores, concepções e } \\
\text { referências, os quais estão embutidos sócio } \\
\text { culturalmente da própria vivência do sujeito } \\
\text { em seu histórico escolar, ressignificando } \\
\text { suas raízes a partir da prática profissional. }\end{array}$ & Obara et al., (2017) \\
\hline $\begin{array}{l}\text { (SERRANO; } \\
\text { PONTES, 2016; } \\
\text { CABALLERO; } \\
\text { BOLÍVAR, 2015; } \\
\text { ROA, 2017; } \\
\text { SISTO, 2012; } \\
\text { VIEIRA, 2011) }\end{array}$ & $\begin{array}{l}\text { Existem dois aspectos fundamentais } \\
\text { presentes na constituição da identidade } \\
\text { profissional docente. Uma trata-se da esfera } \\
\text { intrapessoal relacionada a um fator íntimo; } \\
\text { a outra corresponde à dimensão social } \\
\text { que manifesta no valor social atribuído à } \\
\text { profissão docente. É também determinada } \\
\text { pela realidade econômica, política e social } \\
\text { que os cerca. }\end{array}$ & $\begin{array}{l}\text { Buitrago-Bonilla et al., } \\
\text { (2017) }\end{array}$ \\
\hline (GARCIA, 2009) & $\begin{array}{l}\text { A identidade profissional docente é delineada } \\
\text { como a forma como os professores se } \\
\text { definem a si mesmos e aos outros. É a } \\
\text { construção do seu Eu profissional que se } \\
\text { evolui ao logo de sua carreira docente. }\end{array}$ & $\begin{array}{l}\text { Matos, Nista-Piccolo e } \\
\text { Borges (2016) }\end{array}$ \\
\hline $\begin{array}{l}\text { (BEIJAARD, } \\
\text { BEIJER E } \\
\text { VERLOOP, 2011) }\end{array}$ & $\begin{array}{l}\text { A identidade profissional sugere tanto a } \\
\text { subjetividade do professor como o contexto } \\
\text { em que ele está inserido. }\end{array}$ & $\begin{array}{l}\text { Matos, Nista-Piccolo e } \\
\text { Borges (2016) }\end{array}$ \\
\hline
\end{tabular}




\begin{tabular}{|l|l|l|}
\hline \multirow{2}{*}{ (SACHS, 2001) } & $\begin{array}{l}\text { A identidade docente constitui um processo } \\
\text { negociado, aberto e em manutenção que é } \\
\text { mediado pela experiência dos professores } \\
\text { na escola e fora dela e pelas suas próprias } \\
\text { crenças e valores sobre o que significa ser } \\
\text { professor e o tipo de professor que aspira } \\
\text { ser. }\end{array}$ & Flores (2015) \\
\hline (MELO, 1999) & $\begin{array}{l}\text { A identidade profissional é construída com } \\
\text { base no vínculo com o trabalho educativo. }\end{array}$ & Monteiro (2006) \\
\hline (LESSARD, 1986) & $\begin{array}{l}\text { A identidade profissional traduz-se na } \\
\text { relação que o professor estabelece com } \\
\text { a profissão e com o seu grupo de pares } \\
\text { e implica um processo de construção } \\
\text { simbólica, pessoal e interpessoal que se } \\
\text { consubstancia nas representações sobre os } \\
\text { seguintes aspectos da atividade docente: } \\
\text { capital de saberes, saber-fazer e saber-ser } \\
\text { que fundamentam a prática do professor. }\end{array}$ & Monteiro (2006) \\
\hline GONÇALVES & $\begin{array}{l}\text { A identidade dos professores constrói-se e } \\
\text { reconstrói-se ao longo das diferentes fases } \\
\text { de sua carreira e segundo um processo } \\
\text { evolutivo de natureza construtivista } \\
\text { determinando e sendo determinada pelas } \\
\text { vivência do quotidiano profissional e pessoal } \\
\text { de cada profissional docente. }\end{array}$ & Monteiro (2006) \\
\hline (1996) & & \\
\hline
\end{tabular}

Fonte: Criada pela primeira autora

De acordo com os dados acima, a preferência tem sido pelos estudos de Antônio Nóvoa que referenciou dezoito das vinte e nove pesquisas que apresentaram o conceito de identidade docente. Em segundo lugar, aparece Pimenta referenciada em onze pesquisas. Tardif ocupou o terceiro lugar referenciando três pesquisas. Marcelo e Libâneo aparece como referência e duas pesquisas cada. E, os demais referenciaram uma pesquisa respectivamente conforme exposto no quadro acima.

\section{IDENTIDADES QUE COMPÕEM A IDENTIDADE DOCENTE: CARACTERÍSTICAS PRESENTES NAS PESQUISAS DESTA REVISÃO}

Neste item discute-se as características definidoras da identidade docente apresentadas nas pesquisas em análise. Os dados encontrados são aqui interpretados a partir de quatro categorias principais que agregam outras subcategorias, sendo elas: a identidade missionária, representada nas subcategorias: visão redentora, papel 
feminino, poder e prestígio; a identidade instrumental com as seguintes subcategorias, visão funcionalista, postura centralizadora, controle do Estado; a identidade proletária composta pelas subcategorias: trabalhadores assalariados, luta de classe, precarização das condições de trabalho, relação de poder (explorador / explorado), desprestígio e desvalorização da força de trabalho; e por fim, a identidade profissional que é composta pelas subcategorias: competências e habilidades específicas da profissão, visão interacionista das aprendizagens, razão social da profissão, visão política da educação, consciência de classe, sentimento de pertença e afetividade.

Para situar as discussões aqui suscitadas as principais categorias são aqui compreendidas como:

Identidade missionária, inaugurada no Brasil pelos jesuítas. Por volta da década de 1960, passa a ocupar o cenário educacional brasileiro no modelo da pedagogia agostiniana a qual conferia ao professor uma posição de prestígio por receber a incumbência de transmitir os valores morais da sociedade sob o pilar de uma filosofia cristã, cabendo ao professorado a missão de 'arrebanhar as ovelhas desgarradas'. Em nossa sociedade trata-se dos pobres, dos grupos com culturas religiosas destoantes da cultura hegemônica. (BARROSO, 2004; PATTO, 2006; RODRIGUEZ, 2008)

No que tange à esta categoria, os resultados apontam que as características identitárias á ela vinculada ainda tem um peso muito marcante na identidade docente. Em se tratando das subcategorias a ela relacionada, 'papel feminino', aqui é compreendida como sendo a docência uma extensão de cuidado materno, das atividades do lar, a qual historicamente foi o lugar atribuído à mulher. Com esta definição foram encontradas nove pesquisas (AGUIAR, 2006; OLIVEIRA et al., 2006; FERREIRA, 2007; MIELES-BARRERA, HENRÍQUEZ-LINERO; SÁNCHEZ-CASTELLÓN, 2009; CRUZ; AGUIAR, 2011; TATEO, 2012; NAKAGOME, 2012; BELLIDO, 2015; QUILAQUEO, QUINTRIQUEO; RIQUELME, 2016). A subcategoria 'visão redentora' é aqui entendida como sendo a docência um sacerdócio, o pastor que guiará as ovelhas desgarradas. Estas características foram observadas em treze pesquisas (AGUIAR, 2006; MONTEIRO, 2006; FERREIRA, 2007; ALVES-MAZOTI, 2007; OJEDA, 2008; MALATÉR, 2008; VIEIRA, HYPÓLITO; DUARTE, 2009; MIELES-BARRERA, HENRÍQUEZ-LINERO; SÁNCHEZ-CASTELLÓN, 2009; CUNHA; CARDOZO, 2011; SALES; CHAMON, 2011; TEJERINA; GUTMAN, 2012; SOUZA, PETRONI; ANDRADA, 2013; BELLIDO, 2015). Já a subcategoria 
'poder e prestígio' é aqui interpretada como o poder moralizador sacerdotal incorporado no exercício da docência, que tem como característica o monopólio sobre o certo e o errado. O poder de premiar os comportamentos aprovados e punir os desaprovados por parte da cultura hegemônica da sociedade. Características compatíveis com este perfil foram verificadas em doze pesquisas (MONTEIRO; 2006; AGUIAR, 2006; CUNHA et al., 2007; OLIVEIRA; GRIGOLI, 2008; BRANDO; CALDEIRA, 2009; VERGUEIRO, 2009; CUNHA; CARDOZO, 2011; SALES; CHAMON, 2011; VILLARRUEL FUENTES; PÉREZ SANTIAGO; ALARCÓN SILVA, 2015; ALLAIN; COUTINHO, 2017; BUITRAGO-BONILLA; CÁRDENAS-SOLER, 2017; MARTINS; ANUNCIATO, 2018).

Identidade instrumental é entendida como a identidade forjada a partir da regulação do Estado como medida de controle social. O professor é concebido como instrumento de transmissão dos conhecimentos definidos pelas normatizações do Estado. Neste caso as relações sociais que se estabelecem são pautadas na heteronímia em detrimento da autonomia. Isso é, o professor tendo que obedecer as regulações de controle do Estado assume o papel de regulador social na relação que estabelece com os estudantes no exercício de sua função. Nesta relação a subjetividade é engolida pela racionalização cognitiva. A transmissão do conhecimento se dá por uma única via, o professor transmite e o aluno memoriza, não havendo o exercício dialógico necessário à formação de sujeitos críticos e autônomos, capazes de transformar a realidade e ser por ela transformado (FREIRE, 1992; FERREIRA, 2007). Em relação à esta categoria, percebe-se a manutenção de algumas características semelhantes à identidade missionária como: a centralidade da ação educativa na figura do professor, a busca de manutenção da ordem e do controle, o desejo de poder e prestígio. A diferença está basicamente na substituição do poder sacerdotal pelo poder do Estado.

Em se tratando das subcategorias à ela vinculada, a 'visão funcionalista' diz respeito a um modelo de educação tecnicista centrada nos conteúdos descontextualizados das práticas sociais. Com estas características constituindo a identidade docente foram encontradas oito pesquisas (CUNHA et al., 2007; FERREIRA, 2007; MATHEUS; NACORATO, 2009; CRUZ; AGUIAR, 2011; TATEO, 2012; TEJERINA; GUTMAN, 2012; ROSA; RAMOS, 2015; VILLARRUEL FUENTES, PÉREZ SANTIAGO; ALARCÓN SILVA, 2015). No que tange à subcategoria 'visão centralizadora', esta identifica-se pela centralização da ação pedagógica na figura do professor e nas técnicas 
de ensino, sustentada em uma relação heteronômica em detrimento de uma relação dialógica em que no encontro dos sujeitos educandos e educador estabelece a transformação dos sujeitos e da realidade. Esta centralização abarca também o desejo de poder e prestígio. tal característica como traço na identidade docente foi observada em treze pesquisas (OLIVEIRA; GRIGOLI, 2008; MATHEUS; NACORATO, 2009; BRANDO; CALDEIRA, 2009; VERGUEIRO, 2009; ASSIS, 2010; SALES E CHAMON, 2011; CRUZ E AGUIAR, 2011; TEJERINA; GUTMAN, 2012; VILLARRUEL FUENTES, PÉREZ SANTIAGO E ALARCÓN SILVA, 2015; ROSA; RAMOS, 2015; ALLAIN; COUTINHO, 2017; BUITRAGO-BONILLA; CÁRDENAS-SOLER, 2017; MARTINS; ANUNCIATO, 2018). Quanto à subcategoria 'controle do Estado' observa-se que o sujeito professor reproduz no exercício da docência o controle que o Estado exerce sobre ele. Ou seja, não sendo reconhecido pelo Estado para além de um transmissor de conhecimento a partir de uma visão utilitária do ensino, como instrumento de controle social, tendo a sua autonomia negada, ele reproduz isto com seus alunos. Este traço constituidor da identidade docente, foi verificado em quatorze pesquisas (FERREIRA, 2007; ALVES-MAZOTI, 2007; CUNHA et al., 2007; MATHEUS; NACORATO, 2009; CUNHA; CARDOZO, 2011; SALES; CHAMON, 2011; VERGUEIRO, 2009; CRUZ; AGUIAR, 2011; TEJERINA; GUTMAN, 2012; SOUZA, PETRONI; ANDRADA, 2013; VILLARRUEL FUENTES, PÉREZ SANTIAGO; ALARCÓN SILVA, 2015; ALLAIN; COUTINHO, 2017; BUITRAGO-BONILLA; CÁRDENAS-SOLER, 2017; MARTINS; ANUNCIATO, 2018).

Identidade proletária é aqui vinculada aos fundamentos retirados da teoria de Karl Marx, que funda o Materialismo Histórico, ao analisar a relação que estabelece entre patrão e empregado no sistema industrial capitalista a qual o proletário vende sua força produtiva dentro de um regime de exploração e alienação. (RAITZ; SILVA, 2014; CRUZ; AGUIAR, 2011; MARX, 2008). Em se tratando desta categoria, os resultados encontrados sugeriram a existência de determinadas subcategorias tais como: 'trabalhador assalariado', presente em seis pesquisas (AGUIAR, 2006; MONTEIRO, 2006; FERREIRA, 2007; CRUZ; AGUIAR, 2011; NAKAGOME, 2012; VILLARRUEL FUENTES; PÉREZ SANTIAGO; ALARCÓN SILVA, 2015). A característica da subcategoria 'luta de classe' foi identificada em três (GENTIL, 2006; FERREIRA, 2007; ALVES-MAZOTI, 2007). Com característica da subcategoria 'precarização das condições de trabalho', foram localizadas seis pesquisas (MONTEIRO, 2006; AGUIAR, 2006; 
ALVES-MAZOTI, 2007 MIELES-BARRERA; HENRÍQUEZLINERO; SÁNCHEZ-CASTELLÓN, 2009; CUNHA; CARDOZO, 2011; SOUZA; PETRONI; ANDRADA, 2013). A característica da subcategoria 'relação de poder (explorador / explorado)' foi observada em cinco pesquisas (AGUIAR, 2006; MONTEIRO, 2006; ALVESMAZOTI, 2007; SOUZA; PETRONI; ANDRADA, 2013; RAITZ; SILVA, 2014). Já a característica da subcategoria 'desprestígio e desvalorização da força de trabalho', foi identificada em dez pesquisas (AGUIAR, 2006; MONTEIRO, 2006; FERREIRA, 2007; ALVESMAZOTI, 2007; MIELES-BARRERA; HENRÍQUEZ-LINERO; SÁNCHEZ-CASTELLÓN, 2009; CUNHA, CARDOZO, 2011; SALES; CHAMON, 2011; SOUZA; PETRONI; ANDRADA, 2013; ALLAIN; COUTINHO, 2017; OLIVEIRA, 2017).

Identidade profissional, de acordo com as definições encontradas em algumas das pesquisas, vincula-se à atividade de trabalho sustentada em um conjunto de saberes, competências, habilidades e conhecimentos que o define como características específicas que o diferencia de outros grupos, aferindo assim uma pertença à determinada categoria profissional. (DUBAR, 2005; RAITZ; SILVA, 2014; CRUZ; AGUIAR, 2011). Quanto à esta categoria, os resultados encontrados leva ao entendimento de que as subcategorias que a compõe representam o corpo definidor das especificidades da profissão docente, abarcando tanto os aspectos subjetivos quanto objetivos, o pessoal e social. E que, estes elementos vão sendo incorporados na identidade docente através do processo sócio histórico cultural de acordo com as interações sociais e as representações simbólicas interiorizadas por cada sujeito.

Em relação à subcategoria 'competências e habilidades específicas da profissão’, que engloba tanto o domínio epistêmico quanto metodológico, nesta revisão sistemática, ela foi identificada em dezesseis pesquisas (AGUIAR, 2006; GENTIL, 2006; OJEDA, 2008; MIELES-BARRERA; HENRÍQUEZ-LINERO; SÁNCHEZCASTELLÓN, 2009; FIGUEIREDO, 2010; CRUZ; AGUIAR, 2011; HERNANDEZ, 2011; TATEO, 2012; RAITZ; SILVA, 2014; FLORES, 2015; MIRANDA; CHAVES, 2015; QUILAQUEO; QUINTRIQUEO; RIQUELME，2016; OLIVEIRA，2017; OBARA; BROIETTI; PASSOS, 2017; BUITRAGO-BONILLA; CÁRDENAS-SOLER, 2017; MARTINS; ANUNCIATO, 2018). A subcategoria 'visão interacionista das aprendizagens' foi aqui interpretada como o reconhecimento das aprendizagens como fenômeno social indicada pela valorização das interações entre 
pares. Nesse sentido, a característica presente nesta subcategoria foi encontrada em onze pesquisas (AGUIAR, 2006; GENTIL, 2006; OJEDA, 2008; MIELES-BARRERA; HENRÍQUEZ-LINERO; SĂNCHEZ-CASTELLÓN, 2009; FIGUEIREDO, 2010; ASSIS, 2010; HERNANDEZ, 2011; RAITZ; SILVA, 2014; FLORES, 2015; QUILAQUEO; QUINTRIQUEO; RIQUELME, 2016; MARTINS; ANUNCIATO, 2018). Quanto à subcategoria 'razão social da profissão', é aqui entendida como um substituto da missão, que por sua vez, na identidade profissional não tem a conotação redentora. Mas um papel de agente comprometido com a transformação social através de uma postura dialógica em que educando e educador são protagonistas dos processos de mudança tanto de si quanto da realidade que os circundam (FREIRE, 1992). Com as a características inerentes a esta subcategoria foram identificadas dez pesquisas (AGUIAR, 2006; GENTIL, 2006; OJEDA, 2008; MALATÉR, 2008; MIELES-BARRERA; HENRÍQUEZ-LINERO; SÁNCHEZCASTELLÓN, 2009; TATEO, 2012; RAITZ; SILVA, 2014; MIRANDA e CHAVES, 2015; QUILAQUEO; QUINTRIQUEO; RIQUELME, 2016; OLIVEIRA, 2017). A subcategoria 'visão política da educação', é aqui entendida a partir dos postulados de Freire (1992) que atribui à educação uma intencionalidade, sendo esta a serviço da opressão ou da libertação, da autonomia. Portanto, o exercício da profissão docente é em si uma ação política. O resultado desta revisão evidenciou este traço em sete pesquisas (AGUIAR, 2006; GENTIL, 2006; MIELES-BARRERA; HENRÍQUEZ-LINERO; SÁNCHEZCASTELLÓN, 2009; TATEO, 2012; MIRANDA e CHAVES, 2015; VILLARRUEL FUENTES; PÉREZ SANTIAGO; ALARCÓN SILVA, 2015; OLIVEIRA, 2017). A subcategoria 'consciência de classe' aqui foi criada para interpretar as informações que apareceram nos resultados relacionadas ao reconhecimento de que a sociedade é historicamente marcada por diferenças de oportunidades caracterizando as desigualdades sociais. Nas pesquisas analisadas, esta subcategoria pode ser observada em quatro artigos (GENTIL, 2006; TATEO, 2012; MIRANDA; CHAVES, 2015; QUILAQUEO; QUINTRIQUEO; RIQUELME, 2016). 'Sentimento de pertença', refere-se à subcategoria que revela a docência como um coletivo que possui características específicas que o define enquanto categoria profissional. Os dados referentes às pesquisas analisadas que foram incluídos nesta subcategoria, são os que apresentam características representativas da identificação com a profissão e com suas atribuições. Tais características foram encontradas em nove pesquisas (AGUIAR, 
2006; OJEDA, 2008; MALATÉR, 2008; MIELES-BARRERA; HENRÍQUEZ-LINERO; SÁNCHEZ-CASTELLÓN, 2009; RAITZ; SILVA, 2014; MIRANDA; CHAVES, 2015; OLIVEIRA, 2017; BUITRAGO-BONILLA; CÁRDENAS-SOLER, 2017; MARTINS; ANUNCIATO, 2018). Por outro lado, o sentimento de não pertencimento à coletividade docente esteve presente em quatro pesquisas (MONTEIRO, 2006; FERREIRA, 2007; TATEO, 2012; ALLAIN; COUTINHO, 2017). A subcategoria 'afetividade' é aqui compreendida sob a ótica de Wallon que a concebe como: a disposição do ser humano em ser afetado tanto pelo mundo externo como interno, sendo ela fundante no processo de aprendizagem cognitiva e subjetiva (WALLON, 1995; MABONEY; ALMEIDA, 2005; FERNANDEZ, 2012). Em relação às pesquisas analisadas, o reconhecimento da afetividade na forma de se perceber o ser professor esteve presente em onze artigos. Deste total, em nove, a afetividade aparece ocupando a polaridade positiva (AGUIAR, 2006; OJEDA, 2008; MALATÉR, 2008; VERGUEIRO, 2009; TATEO, 2012; RAITZ; SILVA, 2014; MIRANDA; CHAVES, 2015; QUILAQUEO; QUINTRIQUEO; RIQUELME, 2016; OLIVEIRA, 2017), enquanto que em duas (ALVES-MAZOTI, 2007; SOUZA, PETRONI e ANDRADA, 2013), ela é percebida envolvida em sentimentos negativos à respeito do exercício da profissão docente.

De acordo com os dados levantados, as características definidoras da identidade missionária estiveram presentes em vinte e seis pesquisas. Em relação às subcategorias, constatou-se que mais de uma delas puderam ser verifica na mesma pesquisa. Assim, a subcategoria com maior representatividade foi a 'visão redentora presente em treze artigos; a segunda, 'poder e prestígio’ em doze; e, a terceira, 'papel feminino' em dez.

Em se tratando das características vinculadas à identidade instrumental, os dados revelaram que estas se fizeram presente em vinte artigos. Quatorze referiam à subcategoria 'controle do Estado'; treze à 'postura centralizadora'; e oito, à 'visão funcionalista'.

Quanto à categoria identidade proletária, os resultados apontaram suas características em quinze pesquisas. Deste total, em dez identificou-se a subcategoria 'desprestígio e desvalorização da força de trabalho'; em seis, 'trabalhadores assalariados' e 'precarização das condições de trabalho; em cinco 'relação de poder (explorador/ explorado); e, em três, 'luta de classe'.

No que se refere à categoria identidade profissional, os dados revelaram que esta esteve presente no total de vinte e dois artigos. 
A subcategoria com maior representatividade foi 'competências e habilidades específicas da profissão' presente em dezesseis pesquisas. Em segundo, 'afetividade' e 'visão interacionista das aprendizagens', em onze pesquisas; terceiro, 'sentimento de pertença', em dez; quarto, 'razão social', em nove; quinto, 'visão política da educação', em sete; e, por último, 'consciência de classe', presente em apenas quatro artigos.

Conforme a análise acima, a categoria com maior representatividade nesta revisão foi a categoria identidade missionária que esteve presente em vinte e seis artigos, havendo maior menção em relação à subcategoria 'visão redentora, estando presente em treze artigos e, a subcategoria 'papel feminino' menos mencionada, estando presente em dez. Em segundo lugar encontra-se a categoria identidade profissional evidenciada em vinte e dois artigos desta revisão, sendo a subcategoria mais mencionada 'competências e habilidades específicas da profissão’, presente em dezesseis artigos; e, a menos mencionada é 'consciência de classe', presente somente em quatro artigos. $\mathrm{O}$ terceiro lugar foi ocupado pela categoria identidade instrumental, presente em vinte artigos, sendo a subcategoria com maior representatividade, 'controle do Estado' em quatorze artigos e a menos citada presente em oito artigos a subcategoria 'visão funcionalista'. Em último lugar encontra-se a categoria identidade proletária, presente em quinze artigos, sendo a subcategoria mais citada a 'desprestígio e desvalorização', presente em dez artigos e a menos citada, 'luta de classe' presente apenas em três artigos do total de cinquenta e duas pesquisas desta revisão sistemática.

Importante também citar que, dentre os cinquenta e dois artigos analisados, em seis deles mencionou-se sobre a fase transitória da identidade, corroborando com os enunciados de Bauman (2005), a respeito da crise provocada pela insuficiência dos traços identitários para manter uma identidade estável e de Hall (2006), quando elenca que as mudanças ocorridas no cerne da cultura irá também promover mudança na identidade. 
PANORAMA DASPESQUISAS: QUAL O LUGARDA IDENTIDADE DO PROFESSOR ALFABETIZADOR?

Em relação ao contexto investigativo das pesquisas empíricas aqui analisadas, o quadro abaixo revela esta visão panorâmica:

TABELA 1. Demonstrativo dos artigos em relação ao contexto investigativo.

\begin{tabular}{|c|c|c|c|}
\hline $\begin{array}{l}\text { PESQUISADOR } \\
\text { ANO }\end{array}$ & TítULO & $\begin{array}{l}\text { SUJEITOS } \\
\text { ENVOLVIDOS }\end{array}$ & 0. \\
\hline $\begin{array}{l}\text { Mieles-Barrera, } \\
\text { Henríquez-Linero } \\
\text { Sánchez- } \\
\text { Castellón (2009) }\end{array}$ & $\begin{array}{l}\text { Identidad personal y rofessional de los } \\
\text { docentes de rofessiona en el distrito de Santa } \\
\text { Marta }\end{array}$ & \multirow{2}{*}{$\begin{array}{l}\text { Professores de } \\
\text { Educação Infantil }\end{array}$} & \multirow{2}{*}{2} \\
\hline $\begin{array}{l}\text { Oliveira et al. } \\
\quad(2006)\end{array}$ & $\begin{array}{l}\text { Construção da identidade docente: } \\
\text { Relatos de educadores } \\
\text { De educação infantil }\end{array}$ & & \\
\hline $\begin{array}{l}\text { Alves-Mazoti } \\
\qquad(2007)\end{array}$ & $\begin{array}{l}\text { Representações da identidade docente: uma } \\
\text { contribuição para a formulação de políticas }\end{array}$ & \multirow{7}{*}{$\begin{array}{l}\text { Professores do } \\
\text { Ensino Fundamental }\end{array}$} & \multirow{7}{*}{7} \\
\hline $\begin{array}{l}\text { Vieira, Hypólito e } \\
\text { Duarte (2009) }\end{array}$ & $\begin{array}{l}\text { Dispositivos de regulação conservadora, } \\
\text { currículo e trabalho docente }\end{array}$ & & \\
\hline $\begin{array}{l}\text { Souza, Petroni e } \\
\text { Andrada (2013) }\end{array}$ & $\begin{array}{l}\text { A afetividade como traço da constituição } \\
\text { identitária docente: } 0 \text { olhar da psicologia }\end{array}$ & & \\
\hline Figueiredo (2010) & $\begin{array}{l}\text { Experiências profissionais, identidades e } \\
\text { formação docente em educação física }\end{array}$ & & \\
\hline $\begin{array}{c}\text { Tejerina e } \\
\text { Gutman (2012) }\end{array}$ & $\begin{array}{l}\text { A (re)estabilização identitária do professor no } \\
\text { contexto do ensino de história na Espanha }\end{array}$ & & \\
\hline Salvadori (2007) & Inspirações da memória e identidade docente & & \\
\hline $\begin{array}{l}\text { D'aurea-Tardeli } \\
\qquad(2013)\end{array}$ & $\begin{array}{l}\text { Avaliação dos valores de professores: } \\
\text { possibilidades para uma escola democrática }\end{array}$ & & \\
\hline
\end{tabular}




\begin{tabular}{|c|c|c|c|}
\hline $\begin{array}{l}\text { Hernandez } \\
\text { (2011) }\end{array}$ & $\begin{array}{l}0 \text { sentido das instituições escolares na } \\
\text { Profissão docente desde a perspectiva } \\
\text { biográfica. }\end{array}$ & \multirow{8}{*}{$\begin{array}{l}\text { Professores do } \\
\text { Ensino Médio }\end{array}$} & \multirow{8}{*}{8} \\
\hline Ojeda (2008) & $\begin{array}{l}\text { Rasgos de la rofession del rofessio de } \\
\text { enseñanza media en su trayectoria de } \\
\text { formación y desempeño profesionales. ¿Cómo, } \\
\text { cuándo y con quiénes adquiere su condición } \\
\text { de rofessio? }\end{array}$ & & \\
\hline $\begin{array}{l}\text { Rosa e Ramos } \\
\qquad(2015)\end{array}$ & $\begin{array}{l}\text { Identidades docentes no Ensino Médio: } \\
\text { investigando narrativas a partir de práticas } \\
\text { curriculares disciplinares. }\end{array}$ & & \\
\hline $\begin{array}{l}\text { Obara, Broietti e } \\
\text { Passos (2017) }\end{array}$ & $\begin{array}{l}\text { Contribuições do PIBID para a construçãa da } \\
\text { identidade docente do professor de Química. }\end{array}$ & & \\
\hline $\begin{array}{l}\text { Oliveira e Grigoli } \\
\qquad \text { (2008) }\end{array}$ & $\begin{array}{c}\text { A trajetória escolar: investigando a construção } \\
\text { de uma identidade profissional autônoma de } \\
\text { docentes do Colégio Militar de Campo Grande } \\
\text { MS }\end{array}$ & & \\
\hline $\begin{array}{c}\text { Matheus e } \\
\text { Nacorato (2009) }\end{array}$ & $\begin{array}{l}\text { As influências da políticas públicas } \\
\text { curriculares na constituiçãa da identidade do } \\
\text { professor de Matemática }\end{array}$ & & \\
\hline Assis (2010) & $\begin{array}{l}\text { Saberes, valores e crenças sobre a prática } \\
\text { docente do professor em formação }\end{array}$ & & \\
\hline $\begin{array}{l}\text { Cunha e Cardozo } \\
\text { (2011) }\end{array}$ & $\begin{array}{l}\text { Ensino de História e formação de professores: } \\
\text { narrativas de educadores }\end{array}$ & & \\
\hline $\begin{array}{c}\text { Quilaqueo, } \\
\text { Quintriqueo e } \\
\text { Riquelme (2016) }\end{array}$ & $\begin{array}{l}\text { Identidad Profesional Docente: } \\
\text { Práctica Pedagógica en Contexto Mapuche }\end{array}$ & $\begin{array}{l}\text { Professores } \\
\text { Interculturais }\end{array}$ & 1 \\
\hline $\begin{array}{l}\text { Nakagome } \\
\text { (2012) }\end{array}$ & Identidade docente em formação & & \\
\hline Bellido (2015) & $\begin{array}{l}\text { La construcción de la identidade docente: } \\
\text { investigación narrativa sobre un docente de } \\
\text { lengua extranjera sin formación pedagógica } \\
\text { de base }\end{array}$ & $\begin{array}{l}\text { Professores de } \\
\text { Língua Estrangeira }\end{array}$ & 2 \\
\hline
\end{tabular}




\begin{tabular}{|c|c|c|c|}
\hline $\begin{array}{l}\text { Raitz e Silva } \\
\quad \text { (2014) }\end{array}$ & $\begin{array}{l}\text { Trajetórias identitárias e sentido do trabalho } \\
\text { docente para professores universitários }\end{array}$ & \multirow{3}{*}{$\begin{array}{l}\text { Professores } \\
\text { Universitários }\end{array}$} & \multirow{3}{*}{3} \\
\hline $\begin{array}{c}\text { Villarruel } \\
\text { Fuentes, Pérez } \\
\text { Santiago e } \\
\text { Alarcón Silva } \\
\text { (2015) }\end{array}$ & $\begin{array}{l}\text { Caracterización de la rofession docente a } \\
\text { partir de la comunicación en foros virtuales de } \\
\text { capacitación }\end{array}$ & & \\
\hline $\begin{array}{c}\text { Miranda e } \\
\text { Chaves (2015) }\end{array}$ & $\begin{array}{l}\text { Entre metamorfoses e sentidos: a trajetória de } \\
\text { um professor universitário afrodescendente a } \\
\text { partir dos } \\
\text { pressupostos teóricos da Psicologia Social }\end{array}$ & & \\
\hline $\begin{array}{l}\text { Sales e Chamon } \\
\text { (2011) }\end{array}$ & $\begin{array}{l}\text { Escolha da carreira e processo de construção } \\
\text { da identidade profissional docente }\end{array}$ & \multirow{4}{*}{$\begin{array}{l}\text { Licenciandos em } \\
\text { Pedagogia }\end{array}$} & \multirow{4}{*}{4} \\
\hline $\begin{array}{l}\text { Buitrago-Bonilla } \\
\text { e Cárdenas-Soler } \\
\text { (2017) }\end{array}$ & $\begin{array}{l}\text { Emociones e identidad professional docente: } \\
\text { relaciones e incidencia }\end{array}$ & & \\
\hline $\begin{array}{c}\text { Martins e } \\
\text { Anunciato (2018) }\end{array}$ & $\begin{array}{l}\text { Caminhos de aprendiz de professora: } \\
\text { processos identitários em uma comunidade de } \\
\text { aprendizagem online }\end{array}$ & & \\
\hline Monteiro (2006) & $\begin{array}{l}\text { As representaç̃ões sociais da identidade } \\
\text { docente }\end{array}$ & & \\
\hline
\end{tabular}




\begin{tabular}{|c|c|c|c|}
\hline Malatér (2008) & $\begin{array}{l}\text { Discurso de uma futura professora sobre sua } \\
\text { identidade profissional }\end{array}$ & \multirow{7}{*}{$\begin{array}{l}\text { Licenciandos em } \\
\text { áreas específicas }\end{array}$} & \multirow{7}{*}{7} \\
\hline Vergueiro (2009) & $\begin{array}{l}\text { Identidade de professor: uma pesquisa } \\
\text { fundamentada na psicologia analítica }\end{array}$ & & \\
\hline $\begin{array}{l}\text { Costa e Rezende } \\
\text { (2014) }\end{array}$ & $\begin{array}{l}\text { Construção da identidade docente de um } \\
\text { estudante de licenciatura em Ciências } \\
\text { Biológicas em curso a distância: um caso de } \\
\text { hibridismo }\end{array}$ & & \\
\hline $\begin{array}{l}\text { Allain e Coutinho, } \\
\text { (2017) }\end{array}$ & $\begin{array}{l}\text { Controvérsias em torno das identidades } \\
\text { profissionais de licenciandos em biologia: um } \\
\text { estudo inspirado na teoria ator-rede }\end{array}$ & & \\
\hline Oliveira (2017) & $\begin{array}{c}\text { A bagagem do PIBID para a formação inicial } \\
\text { docente e para a construção da identidade } \\
\text { profissional }\end{array}$ & & \\
\hline $\begin{array}{l}\text { Baladeli, Borstel } \\
\text { e Ferreira (2016) }\end{array}$ & $\begin{array}{l}\text { Identidades docentes e diferença no discurso } \\
\text { de professores de Língua Inglesa em formação } \\
\text { inicial }\end{array}$ & & \\
\hline $\begin{array}{l}\text { Brando e Caldeira } \\
\qquad \text { (2009) }\end{array}$ & $\begin{array}{l}\text { Investigação sobre identidade profissional em } \\
\text { alunos de licenciatura em Ciências Biológicas }\end{array}$ & & \\
\hline Aguiar (2006) & $\begin{array}{l}\text { Implicações da formação continuada para a } \\
\text { construção da identidade docente. }\end{array}$ & \multirow{2}{*}{$\begin{array}{l}\text { Professores em } \\
\text { formação continuada } \\
\text { sem área definida }\end{array}$} & \multirow{2}{*}{2} \\
\hline $\begin{array}{l}\text { Cunha et al. } \\
\text { (2007) }\end{array}$ & $\begin{array}{l}\text { Professor/a: os elementos de uma identidade } \\
\text { em construção }\end{array}$ & & \\
\hline Gentil (2006) & $\begin{array}{l}\text { Identidade de professores e rede de } \\
\text { significações - configurações que constitui o } \\
\text { "nós, professores" }\end{array}$ & $\begin{array}{l}\text { Professores do } \\
\text { Médio Araguaia }\end{array}$ & 1 \\
\hline Flores (2015) & $\begin{array}{l}\text { Identidade docente e formação profissional: } \\
\text { tensões e (des)continuidades }\end{array}$ & $\begin{array}{l}\text { Alunos de curso de } \\
\text { Mestrado em Ensino }\end{array}$ & 1 \\
\hline Soares (2015) & $\begin{array}{l}\text { Os professores do Colégio Pedre II: categorias, } \\
\text { trajetórias e aspectos identitários (1925- } \\
\text { 1945) }\end{array}$ & Análise documental & 1 \\
\hline
\end{tabular}

Fonte: Criada pela primeira autora

De acordo com as informações acima, os sujeitos envolvidos nas pesquisas empíricas com maior índice de investigações foram 
os professores do Ensino Médio, havendo oito pesquisas do total de trinta e nove empíricas. Em segundo com sete pesquisas foram as investigações envolvendo professores do Ensino Fundamental e licenciandos de áreas específicas como. Em terceiro com quatro pesquisas, os licenciandos em pedagogia. O subgrupo professores universitários obteve três pesquisas. Já os subgrupos professores de Educação Infantil, professores de língua estrangeira e professores em formação continuada sem especificar a área de atuação tiveram duas pesquisas em cada. Com uma pesquisa, localizou-se: professores interculturais em contexto Mapoche, professores do Médio Araguaia, alunos de Mestrado em Ensino e uma que foi feito análise documental. Apesar de ter encontrado oito pesquisas com professores do Ensino Fundamental, etapa da Educação básica que abarca o período de alfabetização, não foi localizado nenhuma pesquisa voltada para a compreensão da identidade docente de professores alfabetizadores considerando que trata-se de um campo ainda a ser explorado.

\section{CONSIDERAÇ̃̃ES FINAIS}

Os estudos dirigidos à esta revisão sistemática revelaram que a temática identidade docente vem sendo preocupação de pesquisadores da área educacional como elemento essencial tanto para fomentar processos de formação como práticas pedagógicas. Notou-se que as maiores concentrações se deram nos contextos de: professores do Ensino Médio seguido de professores do Ensino Fundamental e de formação em licenciatura de áreas específicas para graduar professores para atuar na Educação Básica. Constatou-se que, apesar das investigações terem priorizado a construção da identidade docente, há necessidade de mais investigações teóricas e empíricas a respeito das características encontradas, que sugerem que a identidade missionária, a identidade instrumental, a identidade proletária e a identidade profissional tratam-se de aspectos fundantes da identidade docente.

Quanto aos objetivos propostos para esta revisão sistemática, constatou-se que, apesar da questão identidade apresentar-se como um tema em destaque nas investigações de cunho educacional e da psicologia, não se encontrou pesquisas que abordassem diretamente a questão da identidade docente do professor alfabetizador. Considera-se que se trata de uma lacuna que merece uma atenção especial, por este sujeito ser o principal responsável por inscrever a criança na cultura de usuários da linguagem escrita. Além disso, sobre este professor são lançados dois olhares sociais paradoxais. De um 
lado, há uma desvalorização social de sua função de alfabetizar, por carregar culturalmente a representação social de atividade mais ligada à função feminina de cuidado, tratando assim de uma extensão da família mais do que de uma atividade profissional complexa inerente a um corpus de conhecimentos específicos. Por outro lado, ele recebe de seus pares e do Estado, acusações de não ter cumprido o seu papel de preparar os estudantes para serem bons receptores de suas comunicações pedagógicas (BOURDIEU, 2012), prejudicando as aprendizagens subsequentes que dependem da apropriação do capital cultural relacionado à linguagem escrita.

Embora as pesquisas analisadas apontem o sofrimento do professor em decorrência da frustração da ideação de atuação prestigiosa, bem como o sentimento de desvalorização e desamparo como traços de sua identidade docente, observou-se a ausência de investigações que tivessem o contexto de adversidade como cenário de atuação profissional dos sujeitos professores de suas pesquisas. Assim como defendem a maioria dos investigadores estudados, estas pesquisadoras concordam que a identidade docente é construída durante toda a trajetória social do sujeito, extrapolando a sua fase de escolarização, formação e atuação profissional. Neste sentido, considera-se importante pesquisas sobre a constituição da identidade docente em suas dimensões sociológicas e psicológicas. Sugere-se que compreender a identidade docente utilizando diversos referenciais teóricos, como por exemplo, a Psicossociologia e Sociologia Clínica articulada aos pressupostos da Educação Libertadora, poderão lançar luz à compreensão destas identidades que coabitam a identidade docente. Também poderá contribuir com o fomento de programas de formação de professores alfabetizadores e políticas públicas de enfrentamento e superação da dívida social histórica que tem deixado uma grande parcela da sociedade não usuária da linguagem escrita.

\section{REFERÊNCIAS}

AGUIAR, M. da C. C. de. Implicações da formação continuada para a construção da identidade docente. Pic. da Ed., São Paulo, n. 23, $2^{\circ}$ sem., p. 155-173, 2006.

ALLAIN, L. R.; COUTINHO, F. Â. Controvérsias em torno das identidades profissionais de licenciandos em biologia: um estudo inspirado na teoria ator-rede. Educação em Revista, Belo Horizonte, n. 33, p.1-20, 2017.

ALVES, C. J. G.; CALSA, G. C.; MOREL, L. de S. Narrativas biográficas: a formação docente do ponto de vista do aprendente. Constr. Psicopedag., São Paulo, v. 23, n. 24, p. 77-89, 2015. 
ALVES-MAZZOT'TI, A. J. Representações da identidade docente: uma contribuição para a formulação de políticas. Ensaio: aval. pol. públ. Educ., Rio de Janeiro, v. 15, n. 57, p. 579-594, out./dez. 2007.

ASSIS, J. A. Saberes, valores e crenças sobre a prática docente do professor em formação. PERSPECTIVA, Florianópolis, v. 28, n. 2, p. 467-487, jul./dez., 2010.

BALADELI, A. P. D.; BORSTEL, Cl. N., FERREIRA, A. de J. Identidades docentes e diferença no discurso de professores de Língua Inglesa em formação inicial. Revista Portuguesa de Educação, n. 29(1), p. 207-227, 2016.

BARROSO, J. Os novos modos de regulação das políticas educativas na Europa: da regulação do sistema a um sistema de regulações. Educação em Revista, Belo Horizonte, n. 39. p. 19-28, jul. 2004.

BAUMAN, Zygmunt. Identidade: entrevista a Benedetto Vecchi. Rio de Janeiro: Zahar, 2005.

BELLIDO, O. C. La construcción de la identidade docente: investigación narrativa sobre un docente de lengua extranjera sin formación pedagógica de base. Educación, v. 24, n. 46, p. 91-113, mar. 2015.

BOURDIEU, P.; PASSERON, J. A Reprodução. 5ª Ed. Petrópolis, RJ: Vozes, 2012.

BRANDO, F. da R.; CALDEIRA, A. M. de A. Investigação sobre identidade profissional em alunos de licenciatura em Ciências Biológicas. Ciências \& Educação, v. 15, n. 1, p. 155-173, 2009.

BUITRAGO-BONILLA, R. E.; CÁRDENAS-SOLER, R. N. Emociones e identidad profesional docente: relaciones e incidencia. Praxis \& Saber, v. 8. n. 17 - May/Ago., p. 225-247, 2017.

COSTA, M. L. R.; REZENDE, F. Construção da identidade docente de um estudante de licenciatura em Ciências Biológicas em curso a distância: um caso de hibridismo. Revista Ensaio, Belo Horizonte, v.16, n. 01, p. 149-169, jan/abr., 2014.

CRUZ, F. M. L.; AGUIAR, M. da C. C.de. Trajetórias na identidade profissional docente: aproximações teóricas. Psic. da Ed., São Paulo, v. 33, p. 7-28, 2011.

CUNHA, J. L. da; CARDÔZO, L. dos S. Ensino de História e formação de professores: narrativas de educadores. Educar em Revista, Curitiba, n. 42, p. 141-162, out/dez., 2011.

CUNHA, R. B.; FERNANDES, C. H.; MOTA, A. A. D.; NOGUEIRA, E. G. D. Professor/a: os elementos de uma identidade em construção. Pro-Posições, v. 18, n. 1 (52), p. 153-167, jan./abr., 2007.

D'AUREA-TARDELI, D. Avaliação dos valores de professores: possibilidades para uma escola democrática. Est. Ava. Educ., São Paulo, v. 24, n. 56, p. 220-251, set./dez., 2013.

DUBAR, C. A socialização: construção das identidades sociais e profissionais. São Paulo: Martins Fontes, 2005. 
FARIA, E. de; SOUZA, V. L. T. de. Sobre o conceito de identidade: apropriações em estudos sobre formação de professores. Revista Semestral da Associação Brasileira de Psicologia Escolar e Educacional, São Paulo, v. 15, n. 1, p. 35-42, jan./jun. 2011.

FERREIRA, M. O. V. Notas sobre as relações entre identidade e sindicalismo docentes. Educ. Soc., Campinas, vol. 28, n. 99, p. 377-399, maio/ago. 2007.

FERNÁNDEZ, A. A inteligência aprisionada: abordagem psicopedagógica clínica da criança e sua família. Porto Alegre: Artmed, 2011.

FIGUEIREDO, Z. C. C. Experiências profissionais, identidades e formação docente em educação física. Revista Portuguesa de Educação, n. 23(2), p. 153-171, 2010.

FLORES, M. A. Identidade docente e formação profissional: tensões e (des)continuidades. Educação, n 38 (1), p. 138-146, 2015.

FREIRE, P. Educação como prática de liberdade. 21ª ed. Rio de Janeiro: Paz e Terra, 1992.

GENTIL, H. S. Identidade de professores e rede de significações - configurações que constitui o “nóa, professores.” Psic. da Ed., São Paulo, n. 23, 2º sem., p. 175-188, 2006.

HALL, S. A identidade cultural na pós-modernidade. Tradução: Tomaz Tadeu da Silva e Guacira Lopes Louro. Rio de Janeiro: DP\&A, 2006.

HERNANDEZ, R. M. T. O sentido das instituições escolares na profissão docente desde a perspectiva biográfica. Educação em Revista. Belo Horizonte, v. 27, n.1, p. 417-434, abr. 2011.

MALATÉR, L. S. de O. Discurso de uma futura professora sobre sua identidade profissional. Rev. Brasileira de Linguística Aplicada, v. 8, n. 2, p. 445-464, 2008.

MARX, K. O Capital: o processo de produção do capital. Tradução: Reginaldo Santana. 25a ed. Brasil: Civilização Brasileira, 2008.

MARTINS, R. M.; ANUNCIATO, R. M. M. Caminhos de aprendiz de professora: processos identitários em uma comunidade de aprendizagem online. Educação em Revista. Belo Horizonte, n. 34, p. 1-25, 2018.

MATHEUS, A. A. de O. F.; NACORATO, A. M. As influências da políticas públicas curriculares na constituição da identidade do professor de Matemática. ZETETKE CEMPEM - FE/UNICAMP, v. 17, número temático, p. 95-122, 2009.

MATOS, T. S.; NISTA-PICCOLO, V. L.; BORGES, M. C. Formação de professores de Educação Física: identidade profissional docente. Conhecimento \& Diversidade, Niterói, v. 8, n. 15, p. 47-59, jan./jun., 2016.

MIELES-BARRERA, M. D.; HENRÍQUEZ-LINERO, I. M.; SÁNCHEZ-CASTELLÓN, L. M. Identidad personal y profesional de los docentes de preescolar en el distrito de Santa Marta. educ. educ., v. 12, n. 1, p. 43-59, Abr., 2009.

MIRANDA, S. F.; CHAVES, M. M. P. Entre metamorfoses e sentidos: a trajetória de um professor universitário afrodescendente a partir dos pressupostos teóricos da Psicologia Social. Psicologia: ciência e profissão, v. 35, n. 2, p. 584-598, 2015. 
MONTEIRO, I. A. As representações sociais da identidade docente. Cadernos de Estudos Sociais. Recife, v. 22, n. 2, p. 273-286, jul/dez. 2006.

MORGADO, J. C. Identidade profissional docente: sentidos e (im)possibilidades. Ensaio: Aval. Pol. Públ. Educ., Rio de Janeiro, v. 19, n. 73, p. 793-812, out./dez., 2011.

NAKAGOME, P. T. Identidade docente em formação. Linha d'Água, n. 25, v. 1, p. 203$217,2012$.

NETO, S. de S.; BENITES, L. C.; SILVA, M. F. G. da. Da escola de ofício a profissão educação física: a constituição do habitus profissional de professor. Motriz, Rio Claro, v. 16, n. 4 p. 1033-1044, out./dez. 2010.

OBARA, C. E.; BROIETTI, F. C. D.; PASSOS, M. M. Contribuições do PIBID para a construção da identidade docente do professor de Química. Ciênc. Educ., Bauru, v. 23, n. 4, p. 979-994, 2017.

OJEDA, M. C. Rasgos de la identidad del profesor de enseñanza media en su trayectoria de formación y desempeño profesionales. ¿Cómo, cuándo y con quiénes adquiere su condición de profesor? Revista Electrónica de Investigación Educativa, v. 10, n. 2, p. 1-14, 2008.

OLIVEIRA, A. S. de; GRIGOLI, J. A. A. A trajetória escolar: investigando a construção de uma identidade profissional autônoma de docentes do Colégio Militar de Campo Grande MS. PLURES - UMANIDADES: Revista do Programa de Pós-Graduação em Educação Mestrado, Ribeirão Preto, n. 10, jul/dez., 2008.

OLIVEIRA, D. A. Regulação educativa na América Latina: repercussões sobre a identidade dos trabalhadores docentes. Educação em Revista, Belo Horizonte, v. 44. p. 209-227. dez. 2006.

OLIVEIRA, D. A. O trabalho docente na América Latina: identidade e profissionalização. Revista Retrato de Escola, Brasília, v. 2, n. 2-3, p. 29-39, jan./dez., 2008.

OLIVEIRA, H. F. A bagagem do PIBID para a formação inicial docente e para a construção da identidade profissional. Trab. Ling. Aplic., Campinas, n(56.3): 913-934, set./dez. 2017.

OLIVEIRA, Z. de M. R. de, . Construção da identidade docente: relatos de educadores de educação infantil. Cadernos de Pesquisa, v. 36, n. 129, p.547-571, set./dez. 2006.

PATTO, M. H. S. A família pobre e a escola pública: anotações de um desencontro. In: PATTO, M. H. S (org.), Introdução à psicologia escolar. $3^{\mathrm{a}}$ Ed. 2. Reimpressão São Paulo: Casa do Psicólogo, 2006.

QUILAQUEO, D.; QUINTRIQUEO, S.; RIQUELMEAB, E. Identidad Profesional Docente: práctica pedagógica en Contexto Mapuche. Estudios Pedagógicos XLII, n 2 , p. 269-284, 2016.

RAITZ, T. R.; SILVA, C. D L. da. Trajetórias identitárias e sentido do trabalho docente para professores universitários. Psicologia \& sociedade, v. 26, n. 1, p. 204-213, 2014.

RODRIGUEZ, M. V. Reformas educacionais e proletarização do trabalho docente. In: Acta Sci. Human Soc. Sci. Maringá, v. 30, n. 1, p. 45-56, 2008. 
ROSA, M. I. P.; RAMOS, T. A. Identidades docentes no Ensino Médio: investigando narrativas a partir de práticas curriculares disciplinares. Pro-Posições. v. 26, n. 1 (76), p. 141-160, jan./abr. 2015.

SALES, A. de C. M.; CHAMON, E. M. Q. de O. Escolha da carreira e processo de construção da identidade profissional docente. Educação em Revista Belo Horizonte, v. 27, n. 03, p.183-210, dez., 2011.

SALVADORI, M. Â. B. Inspirações da memória e identidade docente. Pro-Posições v. 18, n. 2 (52), p. 167-181, maio/ago., 2007.

SILVA, T. G. da; CARVALHO, M. V. C. de. A dialética da subjetividade versus objetividade desvelando o movimento de se tornar professor. Linguagens, Educação e Sociedade Teresina, PI, ano 11, n. 15, p. 93-104, jul./dez., 2006.

SOARES, J. da C. Os professores do Colégio Pedro II: categorias, trajetórias e aspectos identitários (1925-1945). Ver. Bras. Hist. Educ., Maringá, PR, v. 15, n. 3 (39), p. 293-320, set./dez., 2015.

SOUZA, V. L. T. de; PETRONI, A. P.; ANDRADA, P. C. de. A afetividade como traço da constituição identitária docente: o olhar da psicologia. Psicologia \& Sociedade, v. 25, n. 3 , p. $527-537,2013$.

TATEO, L. What do you mean by “teacher"? Psychological Research on teacher professional identity. Psicologia \& Sociedade; 24 (2), 344-353, 2012.

TEIXEIRA, G. F. M. Docência: uma construção a partir de múltiplos condicionantes. B. Tec. Senac: a R. Educ. Prof., Rio de Janeiro, v. 35, n. 1, jan/abr., 2009.

TEJERINA, J. C.; GUTMAN, I. R. A (re)estabilização identitária do professor no contexto do ensino de História na Espanha. Cad. Cedes, Campinas, v. 32, n. 88, p. 285-301, set/dez. 2012.

VERGUEIRO, P. V. Identidade de professor: uma pesquisa fundamentada na psicologia analítica. Psic. Rev., São Paulo, v. 18, n. 2, p. 203-229, 2009.

VILLARRUEL FUENTES, M.; PÉREZ SANTIAGO, F.; ALARCÓN SILVA, G. Caracterización de la identidad docente a partir de la comunicación en foros virtuales de capacitación. Ciencia, Docencia y Tecnología, n. 26 (50), p. 89-119, May., 2015.

VIEIRA, J. S.; HYPÓLITO; Á. M.; DUARTE, B. G. V. Dispositivos de regulação conservadora, currículo e trabalho docente. Educ. Soc., Campinas, v. 30, n. 106, p. 221-237, jan./abr. 2009.

VOZNIAK, L.; MESQUITA, I.; FAZENDEIRO BATISTA, P. A identidade profissional em análise: um estudo de revisão sistemática da literatura. Educação: Revista do Centro de Educação, Santa Maria, v. 41, n. 2, p. 281-296, maio/ago., 2016.

WALLON, H. Do ato ao pensamento: ensaio de psicologia comparada. Petrópolis, RJ: Vozes, 2008. 
Submetido: 20/06/2018

Aprovado: 08/05/2019

Contato:

Sandra Raquel de Almeida Rua G, Quadra 15, Casa 13|Parque Rio Branco Valparaíso de goiás |GO|Brasil CEP 72.870-022 